\title{
Cluster observation of continuous reconnection at dayside magnetopause in the vicinity of cusp
}

\author{
Y. Zheng ${ }^{1}$, G. Le ${ }^{2}$, J. A. Slavin ${ }^{2}$, M. L. Goldstein ${ }^{2}$, C. Cattell ${ }^{3}$, A. Balogh ${ }^{4}$, E. A. Lucek ${ }^{4}$, H. Rème ${ }^{5}$, J. P. Eastwood ${ }^{1}$, \\ M. Wilber ${ }^{6}$, G. Parks ${ }^{6}$, A. Retinò ${ }^{7}$, and A. Fazakerley ${ }^{8}$ \\ ${ }^{1}$ National Research Council, NASA Goddard Space Flight Center, Greenbelt, MD 20771, USA \\ ${ }^{2}$ Lab. for Solar and Space Phys., Earth-Sun Explor. Div., NASA Goddard Space Flight Center, Greenbelt, MD 20771, USA \\ ${ }^{3}$ University of Minnesota, School of Physics and Astronomy, Tate Lab, Minneapolis, MN 55455, USA \\ ${ }^{4}$ Imperial College, Department of Space and Atmospheric Physics, London, UK \\ ${ }^{5}$ CESR, BP4346, 31028 Toulouse Cedex 4, Toulouse, France \\ ${ }^{6}$ Space Sciences Laboratory, University of California, Berkeley, CA 94720, USA \\ ${ }^{7}$ Swedish Institute of Space Physics, Uppsala Division, Uppsala, Sweden \\ ${ }^{8}$ Dept. of Phys., Mullard Space Sci. Lab., Univ. College London, Holmbury St. Mary, Dorking, Surrey, RH5 6NT, UK
}

Received: 13 January 2005 - Revised: 2 May 2005 - Accepted: 22 May 2005 - Published: 15 September 2005

\begin{abstract}
In this paper, we present a case study of continuous reconnection at the dayside magnetopause observed by the Cluster spacecraft. On 1 April 2003, the four Cluster spacecraft experienced multiple encounters with the Earth's dayside magnetopause under a fairly stable southwestward interplanetary magnetic field (IMF). Accelerated plasma flows, whose magnitude and direction are consistent with the predictions of the reconnection theory (the Walén relation), were observed at and around the magnetopause current layer for a prolonged interval of $\sim 3 \mathrm{~h}$ at two types of magnetopause crossings, one with small magnetic shears and the other one with large magnetic shears. Reversals in the $\mathrm{Y}$ component of ion bulk flow between the magnetosheath and magnetopause current layer and acceleration of magnetosheath electrons were also observed. Kinetic signatures using electron and ion velocity distributions corroborate the interpretation of continuous magnetic reconnection. This event provides strong in-situ evidence that magnetic reconnection at the dayside magnetopause can be continuous for many hours. However, the reconnection process appeared to be very dynamic rather than steady, despite the steady nature of the IMF. Detailed analysis using multi-spacecraft magnetic field and plasma measurements shows that the dynamics and structure of the magnetopause current layer/boundary can be very complex. For example, highly variable magnetic and electric fields were observed in the magnetopause current layer. Minimum variance analysis shows that the magnetopause normal deviates from the model normal. Surface waves resulting from the reconnection process may be involved in the oscillation of the magnetopause.
\end{abstract}

Correspondence to: Y. Zheng

(Yihua.Zheng@jhuapl.edu)
Keywords. Magnetospheric physics (Magnetopause, cusp and boundary layers; Solar wind-magnetosphere interactions) - Space plasma physics (magnetic reconnection)

\section{Introduction}

Since Dungey's (1961) original suggestion that magnetic reconnection should be operative on the dayside magnetopause and the geomagnetic tail, it is believed to be an important mechanism through which the solar wind transfers its mass, momentum and energy across the Earth's magnetopause, then into the magnetosphere. The subsequent energy release via tail reconnection gives rise to substorms and therefore strong aurora. Early indirect evidence supporting magnetic reconnection was found in the correlation of the interplanetary magnetic field (IMF) direction with auroral and magnetic activity on the ground (Arnoldy, 1971; Fairfield and Cahill, 1966; Rostoker and Fälthammar, 1967). Over the years there has been an overwhelming amount of research conducted on or related to magnetic reconnection. Convincing evidence can be found in the in-situ observations at the magnetopause: from the ISEE and AMPTE satellites (e.g. Paschmann et al., 1979, 1986; Sonnerup et al., 1981, 1987, 1990, 1995; Gosling et al., 1982, 1986, 1990c, 1991; Aggson et al., 1983), recently by IMAGE (e.g. Fuselier et al., 2000), POLAR (e.g. Scudder et al., 2002; Mozer et al., 2002), WIND (e.g. Phan et al., 2001), Cluster (e.g. Phan et al., 2003), and from joint observations of multiple spacecraft (Phan et al., 2000, 2003; Frey et al., 2003).

Most of the magnetic reconnection studies mentioned above have invoked accelerated flows of magnetosheath plasma in the vicinity of the magnetopause and in the 
magnetospheric boundary layer as evidence of magnetic reconnection. Since the dayside magnetopause structure during reconnection consists of a rotational discontinuity, as proposed by Levy et al. (1964), the approximate agreement of the accelerated flows with the so-called Walén relation, which is based on the tangential stress balance across a onedimensional, time-stationary, rotational discontinuity, is often used as strong evidence for the occurrence of reconnection. Various aspects of accelerated flow events have been reported in the previous studies, such as their location and occurrence rate, comparisons with the theoretical predictions via the Walén relation test (Paschmann et al., 1979; Gosling et al., 1982, 1986, 1990c), the details of electron and ion distribution in the region where they are observed, the characteristics of density and temperature in comparison to their adjacent regions (Gosling et al., 1990a, b), and their relationship to geomagnetic activities and corresponding IMF conditions (e.g. Scurry et al., 1994 a,b and Phan et al., 1996). Using AMPTE/IRM data, Phan et al. (1996) found that the occurrence of accelerated flows is independent of local magnetic shear, local time/latitude, local tangential magnetosheath flow speed and local magnetosheath Alfvén Mach number. They also confirmed an earlier result which found that the agreement with the Walén relation worsens with increasing $\beta$ ( $\beta$ is the ratio of plasma pressure to magnetic pressure). In short, past research efforts have revealed many features associated with accelerated flows, and therefore the manifestations and characteristics of magnetic reconnection. However, despite many reported accelerated plasma flow events in the literature, observation of accelerated plasma flows with a long duration has been rare (Gosling et al., 1982; Phan et al., 2004; Retinò et al., 2005).

In this paper, we present such an event, during which a prolonged interval of accelerated plasma flow $(\sim 3 \mathrm{~h})$ was observed at the dayside magnetopause by Cluster spacecraft around the northern cusp under southwestward IMF. During this three-hour interval, the four Cluster spacecraft were at the radial distance $\mathrm{r} \sim 8.4-11.3 R_{E}$, with MLT $\sim 09: 06-10: 18$ and MLAT $\sim 72^{\circ}-66^{\circ}$. Other signatures of magnetic reconnection, such as flow reversal of the y-component of ion bulk velocity between the magnetosheath and the magnetopause current layer and the acceleration of magnetosheath electrons and ions in the magnetopause current layer, were also observed. Recently, the question of whether reconnection is continuous or intermittent has once again drawn considerable attention. Using imaging data of proton aurora (interpreted to be the ionospheric signature of dayside magnetopause reconnection) from the IMAGE satellite, Frey et al. (2003) showed that the reconnection process can be continuous for quite a long time. Their result of continuous reconnection is derived from the ionospheric signatures. In order to use ionospheric signatures to probe the magnetopause, field line tracing has to be invoked, which depends on the accuracy of the magnetic field model utilized. The Cluster event described herein, on the other hand, provides strong in-situ evidence that magnetic reconnection at the dayside magnetopause can be continuous for many hours. However, the reconnection process appeared to be very dynamic rather than steady, despite the steady nature of the IMF. The particular merit of this study is that this Cluster event provides in-situ evidence of continuous reconnection and that the multiple instruments and multiple spacecraft of Cluster allow us to more closely examine the structure and dynamics of the magnetopause in the presence of reconnection. Qualitative analyses using the multi-spacecraft field and plasma measurements show that the dynamics and structure of the magnetopause current layer/boundary can be very complex. Highly variable magnetic fields and depression in the magnitude of the magnetic fields, along with large electric fields, were observed in the magnetopause current layer.

This paper is organized as follows: a brief description of the instrumentation used for the event study is given in Sect. 2. Section 3 contains an overvie of the event and Sect. 4 provides a detailed analysis of the accelerated flows and their associated particle signatures. A discussion is in Sect. 5 and a summary of the study is given in Sect. 6 .

\section{Instrumentation}

The contributing Cluster instruments for this case study are FGM (Flux Gate Magnetometers) for 3-D measurement of the magnetic field vector (Balogh et al., 2001), HIA (hot ion analyzer) of CIS (Cluster Ion Spectrometer) (Rème et al., 2001) for ion measurement, and PEACE (Plasma Electron and Current Experiment) for electron parameters (Johnstone et al., 1997). We also used measurements made by ACE (Advanced Composition Explorer) spacecraft. The solar wind velocity was obtained by the Solar Wind Electron, Proton, and Alpha Monitor (SWEPAM) (McComas et al., 1998) and the tri-axial fluxgate magnetometer (Smith et al., 1998) on ACE supplied interplanetary magnetic field data.

\section{Event overview}

In this study, we focus on an event observed by Cluster during 00:00-03:30 UT on 1 April 2003. This is an outbound pass near the cusp and the magnetopause at high latitude $\left(72^{\circ} \sim 66^{\circ}\right.$ MLAT), mostly in the northern dawn sector (9-10 MLT). The separation between the Cluster spacecraft was about $1 R_{E}$. The most striking feature of the event is that during almost the entire interval of interest, accelerated flows were observed whenever the Cluster spacecraft were at/around the magnetopause/boundary layer. For each of the four spacecraft, different regions can be identified based on the particle measurements from CIS and PEACE. Taking Cluster 3 (C3) as the reference spacecraft, Cluster first encountered the plasma mantle layer with a density of around $0.3 \mathrm{~cm}^{-3}$; then, as the spacecraft moved outward and southward, it traversed the cusp/cleft region, followed by the magnetopause/boundary layer interface, and finally exited into the magnetosheath region. Because of the relatively large separations between the four spacecraft, each traversed 
different regions at slightly different times. Details of the particle observations are given below.

\subsection{Orbit}

Figure 1 shows the projection of Cluster 3's trajectory (the green curve in the figure) in the $X_{G S M}-Z_{G S M}$ plane and the $X_{G S M}-Y_{G S M}$ for the event. On 1 April 2003, Cluster crossed the high-altitude cusp near local noon at a radial distance of about 8.4 11.3 $R_{E}$. The arrow shown in the $X_{G S M}-Z_{G S M}$ plane indicates the direction of the trajectory. In the $X_{G S M}-Y_{G S M}$ plane, the spacecraft moved towards more negative $Y_{G S M}$ and towards noon as time progressed. The green asterisks along the trajectory are the spacecraft's position at 00:00, 00:10, 01:00, 01:30, 02:00, 02:30 and 03:00 UT, respectively. The magnetic field lines at these locations, using the Tsyganenko 96 (T96) model (Tsyganenko, 1995), projected into the planes, are also shown. The regions traversed based upon the model field lines in general agree with the observations of both fields and particles. Also shown in Fig. 1 is the tetrahedron made up by the four spacecraft at 01:30 UT, with C4 leading and C3 trailing behind (for the purpose of clarity, the separation distance relative to spacecraft 3 was multiplied by a factor of 5.0). The tetrahedral configuration did not change much for the interval of interest (00:00-03:30 UT). Throughout this paper, we will use black for spacecraft 1 (C1), red for spacecraft 2 (C2), green for spacecraft 3 (C3) and blue for spacecraft 4 (C4), unless otherwise specified.

\subsection{Interplanetary conditions}

The upstream solar wind and interplanetary magnetic field (IMF) measurements in geocentric solar magnetospheric (GSM) coordinates from ACE are shown in Fig. 2. The data in Fig. 2 is already time-shifted by $54.4 \mathrm{~min}$, which is obtained by matching the sudden northward turning of the IMF measured at both ACE and Cluster. The northward turning took place around 03:34:46 UT for Cluster 1 and 02:40:22 for ACE (not shown here since it is outside the interval of interest). From top to bottom, Fig. 2 shows the solar wind proton density, speed, dynamic pressure, IMF clock angle (defined as $\tan ^{-1}\left(B_{y} / B_{z}\right)$ ), IMF $B_{x}, B_{y}, B_{z}$ and $|\mathbf{B}|$. During these three and one-half hours, the average solar wind speed was about $500 \mathrm{~km} / \mathrm{s}$, the density was about $2.3 \mathrm{~cm}^{-3}$, the dynamic pressure was $1.0 \mathrm{nPa}$ and the average clock angle was about $-160^{\circ}$. The IMF $B_{x}$ was positive, and $B_{y}$ and $B_{z}$ were both negative. Prior to this event, the IMF $B_{z}$ had been mostly southward for about $17 \mathrm{~h}$, which resulted in strong auroral activity, indicating that the solar wind-magnetosphereionosphere coupling was effective.

\subsection{Event overview}

Overviews of the event are given in Figs. 3, 4 and 5. Figure 3 contains the ion moment data (such as velocity, density and temperature) in the context of the magnetic field for the whole three and one-half hour interval. The purpose of
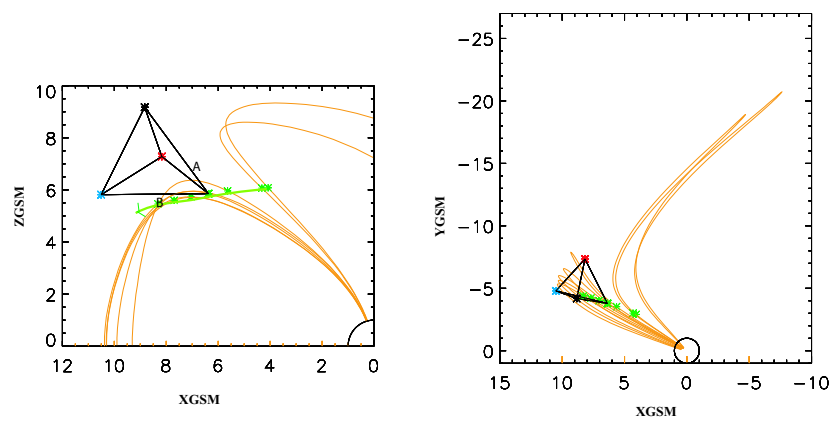

Fig. 1. The trajectory and the configuration of the Cluster quartet during the event with regard to the magnetic fields in $X_{G S M}-Z_{G S M}$ and $X_{G S M}-Y_{G S M}$ planes. The magnetic field lines are derived from the T96 model using the solar wind and IMF conditions at the time. The green asterisks along the trajectory are the spacecraft position at 00:00, 00:10, 01:00, 01:30, 02:00, 02:30 and 03:00 UT, respectively. Also shown in Fig. 1 is the tetrahedron made up by the four spacecraft at 01:30 UT (for the purpose of clarity, the separation distance relative to $\mathrm{C} 3$ was multiplied by a factor of 5.0) with $\mathrm{C} 1$ in black, $\mathrm{C} 2$ in red, $\mathrm{C} 3$ in green and $\mathrm{C} 4$ in blue.

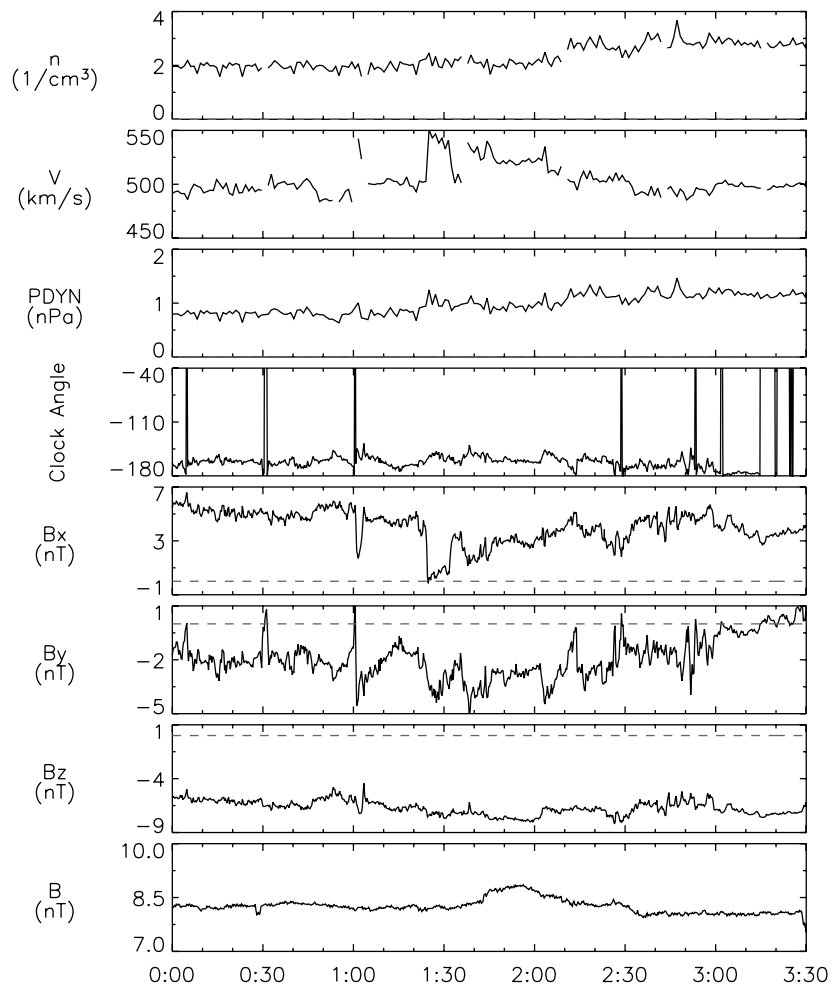

Fig. 2. The solar wind and IMF measurements in GSM from the ACE spacecraft. The time is shifted by $54.4 \mathrm{~min}$ to match the sudden northward turning of the IMF measured at both the ACE and the four Cluster spacecraft. Notice the IMF $B_{z}$ was negative throughout the whole interval. The IMF $B_{y}$ was also negative.

this plot is to emphasize the long-lasting accelerated flows. Complementary to Figs. 3, 4 and 5 are two subsets of the event where both electron and ion energy-time spectrograms are shown. The regions traversed by the Cluster spacecraft 


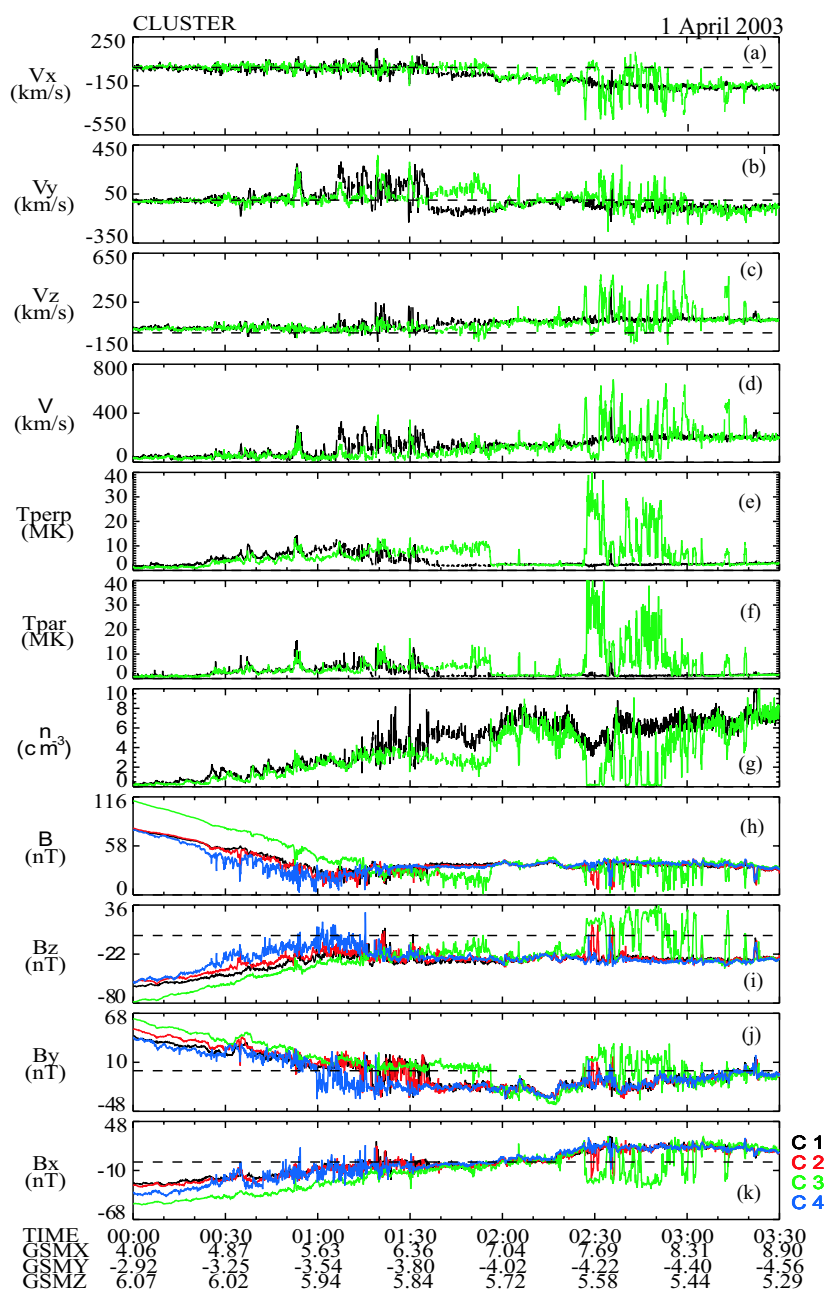

Fig. 3. The overview of the event showing the particle and the magnetic field data. The top seven panels are the particle parameters obtained using HIA (only operative in C1 and C3). From top to bottom are the three components of the ion bulk velocity, its magnitude, the perpendicular and the parallel temperature, and the density, respectively. The magnitude and the three components of the magnetic field for all of the four spacecraft are shown in the bottom four panels. The color scheme to represent the four spacecraft is the standard one: with $\mathrm{C} 1$ in black and $\mathrm{C} 2$ in red, and $\mathrm{C} 3$ in green and $\mathrm{C} 4$ in blue.

and the properties of each region are best seen from Figs. 4 and 5 .

Shown in the top seven panels of Fig. 3 are ion measurements from the HIA instruments on $\mathrm{C} 1$ and $\mathrm{C} 3$ (only operational on $\mathrm{C} 1$ and $\mathrm{C} 3$ ). The bottom four panels of Fig. 3 are the measurements of the magnetic field from the four spacecraft. Figure $3 \mathrm{a}$ is the $\mathrm{x}$-component of the ion bulk velocity and $b, c, d$ show the $y-$, z-components and magnitude, respectively. The ion perpendicular and parallel temperatures are shown in Figs. $3 \mathrm{e}$ and $\mathrm{f}$. Figure $3 \mathrm{~g}$ is the ion density. The magnitude and the three components $(\mathrm{x}, \mathrm{y}, \mathrm{z})$ of the magnetic field are shown in $\mathrm{h}, \mathrm{k}, \mathrm{j}$ and $\mathrm{i}$, respectively.
The most noticeable feature in Fig. 3 is that accelerated flows were detected during the time from about 00:50 UT to 3:20 UT, whenever Cluster encountered a magnetopause/boundary crossing, indicating that magnetic reconnection can be continuous for many hours.

During the course of their outbound traversal from the plasma mantle poleward of the cusp, through the cusp, to the magnetopause boundary, and finally into the magnetosheath, the Cluster spacecraft encountered the magnetopause boundary numerous times. Mainly due to the motion of the magnetopause, these encounters occurred in two general regions: (A) near the equator-edge of the northern cusp, where the open-closed field line boundary probably resides (roughly where A is in Fig. 1 and $\sim 00: 50-01: 40$ UT in Fig. 3), and the magnetic shear between the magnetosheath-like region and the magnetospheric-like region was small; and (B) the dayside magnetopause boundary equatorward of the cusp (roughly where B is in Fig. 1 and $\sim 02: 00-03: 30$ UT in Fig. 3), and the magnetic shear across the magnetopause was large (close to $180^{\circ}$ ). Due to the specific configuration of the four spacecraft and the motion of the magnetopause boundary, $\mathrm{C} 1, \mathrm{C} 2$ and $\mathrm{C} 4$ had multiple crossings with the first type of magnetopause at different times, while $\mathrm{C} 3$ did not, as it was trailing the other three. For the same reason, when C3 crossed the second type of magnetopause multiple times, the other three spacecraft were mostly in the magnetosheath and had only a few partial or no encounters with the magnetopause.

Because HIA data are only available from $\mathrm{C} 1$ and $\mathrm{C} 3$, the overview of the first type of boundary crossings (low magnetic shear) is better viewed using HIA data from $\mathrm{C} 1$ (see the shaded region in Fig. 4) and the overview of the second type of boundary crossings (high magnetic shear) is shown as the highlighted region in Fig. 5, using data from C3. Figures 4 and 5 have the same format: from top to bottom, one sees the electron energy-time spectrogram, the ion energytime spectrogram, assuming that the ions are protons, the density in $\mathrm{cm}^{-3}$, the three components of the proton velocity in GSE ( $\mathrm{x}$ in red, $\mathrm{y}$ in green and $\mathrm{z}$ in blue), the proton temperature (with the perpendicular temperature in blue and the parallel temperature in magenta and the total temperature in black), and $B_{x}, B_{y}, B_{z}$ in GSE and B, respectively. The timeenergy spectra of both ions and electrons (Figs. 4 and 5) of the event show that the four spacecraft traversed through different plasma regions during the interval of 00:00-03:30 UT. These regions include: (1) the plasma mantle (from 00:00 UT to about 00:23 UT for $\mathrm{C} 1$ in Fig. 4), with a very small plasma density $\left(\sim 0.2 \mathrm{~cm}^{-3}\right)$; (2) the cusp (00:23-00:50 UT), characterized by enhanced density (sometimes reaching to 1.0 $2.0 \mathrm{~cm}^{-3}$ ) of magnetosheath-like plasma; (3) the boundary plasma sheet (BPS, 00:50 UT 01:13 UT), with an obvious presence of energetic ions and electrons $(10 \mathrm{keV}$ above for ions and $1 \mathrm{keV}$ above for electrons); (4) the magnetosheath region close to the magnetopause (01:55 02:00 UT in Fig. 4 and 03:25-03:30 UT in Fig. 5), with the majority of electrons in the $50-200 \mathrm{eV}$ range, and ions in the $40 \mathrm{eV}-4000 \mathrm{eV}$ range and an average ion density of a few $\mathrm{cm}^{-3}$; and (5) 


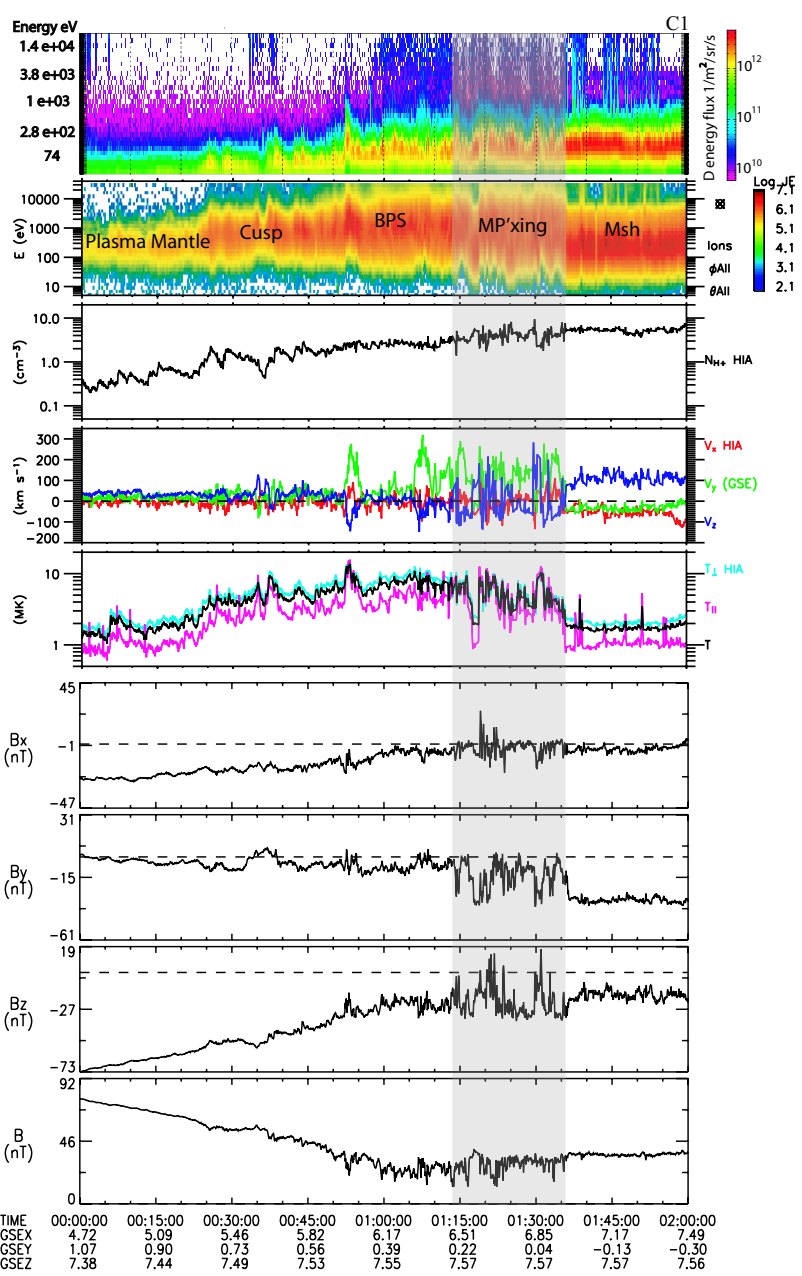

Fig. 4. The overview of the boundary crossings with small magnetic shear. The top panel is the electron energy-time spectrogram, the next four panels show the ion data from HIA and the bottom four panels are the magnetic field data. From top to bottom is the electron energy-time spectrogram, the ion energy-time spectrogram, density, the three components of velocity in GSE coordinates with the $\mathrm{x}$ component in red, $\mathrm{y}$ in green and $\mathrm{z}$ in blue), the parallel (red) and the perpendicular (blue) temperature, the $\mathrm{x}$ component of the magnetic field in GSE- $B_{x}, B_{y}, B_{z}$ and $\mathrm{B}$, respectively. Notice the different regions traversed by the spacecraft, as shown in the top panel.

the magnetopause boundary layers where the accelerated flows were observed. The first type of boundary layer is the interface between the polar cusp and the magnetosphere. The plasma within shows alternations between the BPS-like plasma and magnetosheath-like plasma (Fig. 4). The second type of boundary layer is the dayside magnetopause just equatorward of the cusp, i.e. the interface between the magnetosheath and the dayside magnetosphere. The plasma there oscillates between the magnetosheath and magnetosphere proper (Fig. 5). Note that, prior to the highlighted region in Fig. 5, C3 was located in the magnetosheath, but had two excursions (at around 02:05 UT and 02:17 UT) into the magnetopause/boundary layer, as evidenced by both the

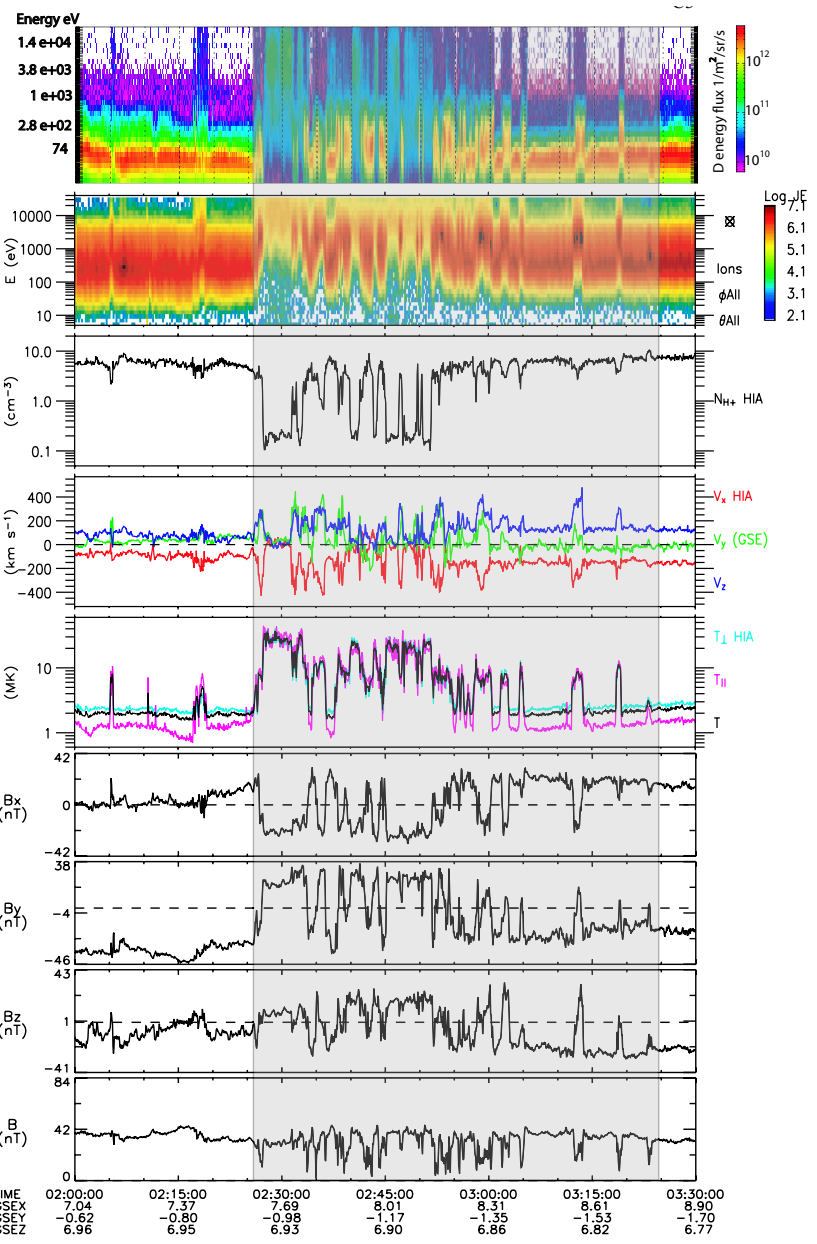

Fig. 5. The overview of the boundary crossings with large magnetic shear. Figure 5 has the same format as Fig. 4.

particle and the field parameters shown in Fig. 5. The multiple magnetopause encounters of Fig. 5 show that throughout the whole interval, the motion and/or the structure of the magnetopause were rather complex.

\section{Analyses of the accelerated flows and implications for continuous reconnection}

\subsection{Characteristics of the accelerated flows}

The accelerated flows were observed at both types of magnetopause boundary crossings, one with a small magnetic shear and the other with a large magnetic shear. These flows exhibit the following common characteristics based on Figs. 4 and 5 .

1. The accelerated flows had very large flow speed compared to the magnetosheath plasma, at times reaching $\sim 700 \mathrm{~km} / \mathrm{s}$ (exceeding their adjacent magnetosheath flow speed by $\sim 550 \mathrm{~km} / \mathrm{s}$ ) and persisted for a long time - almost $3 \mathrm{~h}$. The ion $\beta$ in the magnetosheath was about $0.2-0.5$ during the event. This low $\beta$ value favors the 
occurrence of accelerated flows as showed by Scurry et al. (1994a).

2. Whenever there was accelerated flow, there was a rotation or at least change in magnetic field.

3. Of all the observed high-speed jets, the peak of the flow speed occurred at the earthward edge (magnetospheric side) of the current layer (Gosling et al., 1986), as expected (Sonnerup et al., 1995).

4. Within the accelerated flows, the ion density was usually smaller than that observed in the adjacent magnetosheath but slightly larger than that of the adjacent magnetosphere. The temperatures within the accelerated flows were between the values of the magnetosheath and the magnetosphere, but closer to those of the magnetosheath.

5. For most of the observed flows, the magnitude of the magnetic fields was roughly the same on both sides of the magnetopause, but it was greatly reduced within the magnetopause current layer. The presence of such field depressions is common in the magnetopause current layer and has been reported in other reconnection events (e.g. Paschmann et al., 1979; Gosling et al., 1986, 1990c, 1991; Phan et al., 2001, Mozer et al., 2002).

6. The accelerated flows were in the positive $y$ and $z$ directions, i.e. the plasma had duskward and northward acceleration, which agrees with the jet direction resulting from magnetic reconnection based upon the configuration of magnetic fields in the magnetosheath (negative $B_{y}$ and negative $B_{z}$ ). When $B_{y}$ (IMF $B_{z}$ negative) is negative, the force pulls the plasma towards northeast in the Y-Z plane in the northern dawn quadrant and the opposite direction in the southern dusk quadrant (see the bottom panel of Fig. 1 in Gosling et al. (1990c)).

7. Flow reversals were observed throughout the event, i.e. the y-component of the flow within both the high latitude boundary layer (magnetospheric side) and the magnetopause current layer had the opposite sign $\left(+V_{y}\right.$, duskward) from that within the adjacent magnetosheath $\left(-V_{y}\right.$, dawnward). The flow reversals in the y component of the ion bulk velocity are the result of magnetic reconnection, as described in Gosling et al. (1990c).

Figure 6 illustrates the observed flow reversals (second panel, $V_{y}$; the gaps are due to missing data) at the two types of magnetopause crossings. The shaded areas of Fig. 6 highlight the magnetosheath region, where the y-component of the plasma, flow was opposite (negative $V_{y}$ ) to that within the magnetopause and its earthward boundary layer (positive $\left.V_{y}\right)$.
4.2 Fluid signature of reconnection - tangential stress balance tests

In this section, we show quantitatively that the accelerated flows are reconnection jets by performing the tangential stress balance tests. First, using the tangential stress balance relation, we calculate the predicted velocity for extended intervals based on a single magnetosheath reference point. Then we show that the high-speed flows satisfy the Walén relation, which is often used as strong (if not incontrovertible) evidence that magnetic reconnection was occurring or had been occurring in the immediate past at the magnetopause.

During reconnection, the magnetopause consists of a rotational discontinuity (RD) (Levy et al., 1964). The tangential stresses at an RD can lead to deceleration of the plasma as well as acceleration, depending upon the geometry of the external magnetic field and plasma flow. For an RD, ideal MHD predicts that the flow is Alfvénic in the deHoffmannTeller (HT) frame of reference (Hudson, 1970):

$\rho(1-\alpha)=$ const .

$\mathbf{v}-\mathbf{V}_{H T}= \pm(1-\alpha)^{1 / 2} \mathbf{B} /\left(\mu_{0} \rho\right)^{1 / 2}$,

where $\rho$ is the total mass density and $\alpha \equiv\left(\mathrm{P}_{\|}-\mathrm{P}_{\perp}\right) \mu_{0} / \mathrm{B}^{2}$ is the pressure anisotropy factor $\left(\mathrm{P}_{\|}\right.$and $\mathrm{P}_{\perp}$ are the plasma pressure parallel and perpendicular to $\mathbf{B})$, $\mathbf{v}$ is the plasma velocity, $\mathbf{V}_{H T}$ is the deHoffmann-Teller velocity, the motion of the open flux tubes along the magnetopause resulting from the magnetic tension force $\left(\mathbf{V}_{H T}=E_{t} \times B_{n} / B_{n}^{2}\right.$, where $E_{t}$ is the tangential electric field and $B_{n}$ is the normal magnetic field), and $\mathbf{B}$ is the magnetic field. The right-hand side of Eq. (2) represents the Alfvén velocity. Equation (2) is also called the Walén relation.

\subsubsection{Test using a single reference point}

Before performing the Walén test, we will first show a quantitative evaluation of the agreement between the predicted and the observed high-speed flows at both types of boundaries based on a single magnetosheath reference point (Phan et al., 2004). From Eqs. (1) and (2), we can obtain the following relation:

$$
\begin{gathered}
\Delta v_{\text {predicated }}=v_{2 t}-v_{1 t}=+\left(1-\alpha_{1}\right)^{1 / 2} \mu_{0} \rho_{1}^{-1 / 2} \\
{\left[B_{2 t}\left(1-\alpha_{2}\right) /\left(1-\alpha_{1}\right)-B_{1 t}\right]}
\end{gathered}
$$

The positive sign was chosen because the Cluster spacecraft were above the potential reconnection site. Subscript " 1 " is used to represent the magnetosheath reference point and " 2 " is used to represent any other times for calculating the predicted velocity. The results at the first type (low magnetic shear) of boundary crossing (using $\mathrm{C} 1$ data) are shown in Fig. 7 and those at the high-magnetic shear crossings (from C3 measurements) are shown in Fig. 8. For both Figs. 7 and 8 , the top three panels are the time-shifted ACE data of the interplanetary magnetic field. The bottom three panels show the measured HIA (in black) and the predicted (in 
C1 - flow reversal at 1st type of MP'xing

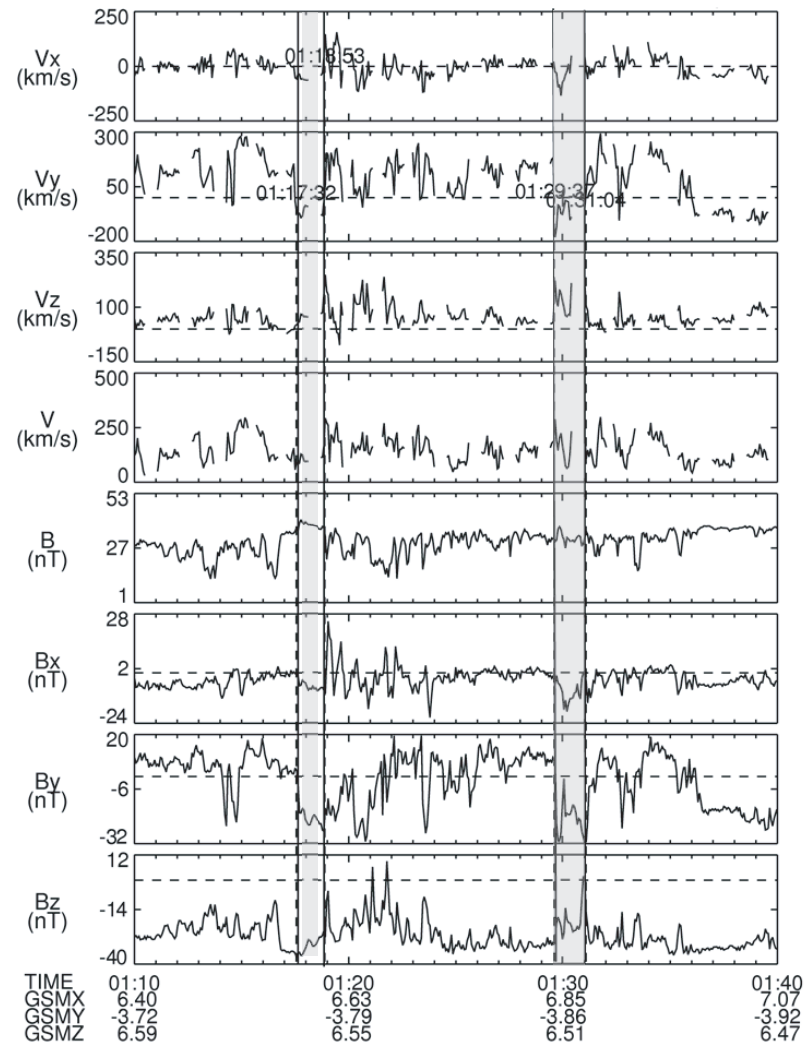

C3 - flow reversal at 2nd type of MP'xing

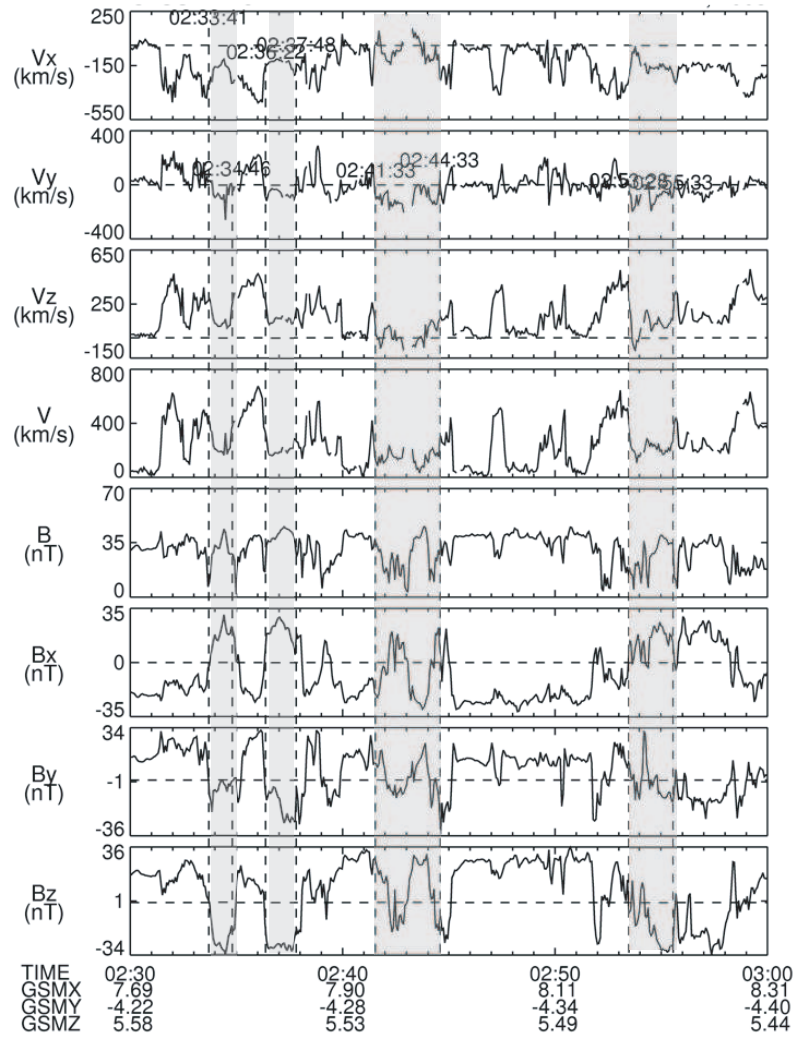

Fig. 6. Flow reversals in the y component of the ion bulk flow are shown for two types of magnetopause crossings. The left and the right panels are for the first and second type of crossing respectively. The shaded regions in the plot are used to highlight the magnetosheath region where the flow has negative $\mathrm{V}_{y}$, opposite to that of the magnetopause and its boundary layers.

red) velocity in boundary normal coordinates using the magnetopause model by Shue et al. (1997). For Fig. 7, the magnetosheath reference point is at 01:41 UT (the dashed line). For the Fig. 8 calculation, the reference point is at 03:09 UT and is also marked by the dashed line in the plot. This test works best when the IMF condition is relatively steady. Despite the somewhat varied IMF conditions and, therefore, the variations in the sheath magnetic field, Fig. 7 shows that the predicted velocity tracks the measured velocity well. Since the points at the beginning of the period are more than half an hour away from the reference point, the agreement is not perfect. Figure 8 has the same format as Fig. 7, except that the green asterisks show the predicted velocity when the density is higher than $5 \mathrm{~cm}^{-3}$. By looking at the black and the red lines in Fig. 8, the first impression is that the agreement between the measurements and the predicted values is not very good, especially at the beginning of the interval. If we look at Fig. 8 more carefully, however, we find that the disagreements occurred when C3 was either at the magnetosphere or at the inner part of the boundary layer, which is no longer an RD (Phan et al., 2001). The reconnection layer consists of an outer RD, followed by a region of uniform flow and field and then an inner slow mode expansion fan according to MHD models of dayside reconnection. This point can be demon- strated by comparing the predicted velocity when the density is higher than $5 \mathrm{~cm}^{-3}$ (about half of the magnetosheath density) and the measured velocity (the green asterisks and the black line in Fig. 8). The density condition applied here is to make sure that the comparison is made across the RD only. We can see that the agreement is improved. The slow ion sampling rate (a sample every $4 \mathrm{~s}$ ) plus the additional missing data may contribute to the disagreement, as well. As mentioned above, even though the IMF condition for this event was not very steady, the results displayed in Figs. 7 and 8 show that the high-speed flows are most likely the result of magnetic reconnection.

\subsubsection{Walén relation test}

The Walén relation states that in the deHoffmann-Teller (HT) frame, the flows are field-aligned and Alfvénic. The HT frame for a set of plasma measurements can be found by minimizing the mean square of the convection electric field, $\mathrm{D}(\mathbf{v})=<\mid\left(\mathbf{v}-V_{H T} \times\left.\mathbf{B}\right|^{2}>\right.$ (Sonnerup et al., 1987). In the HT frame, the convection electric field ideally should vanish. The velocity $\mathbf{v}$ at which $\mathrm{D}(\mathbf{v})$ is a minimum is the deHoffmann-Teller velocity, $V_{H T}$. The ratio of $D_{H T} / D_{0}$ $\left(D_{H T}\right.$ is $\mathrm{D}(\mathbf{v})$ at its minimum and $D_{0}=<|\mathbf{v} \times \mathbf{B}|^{2}>$ ) is often 


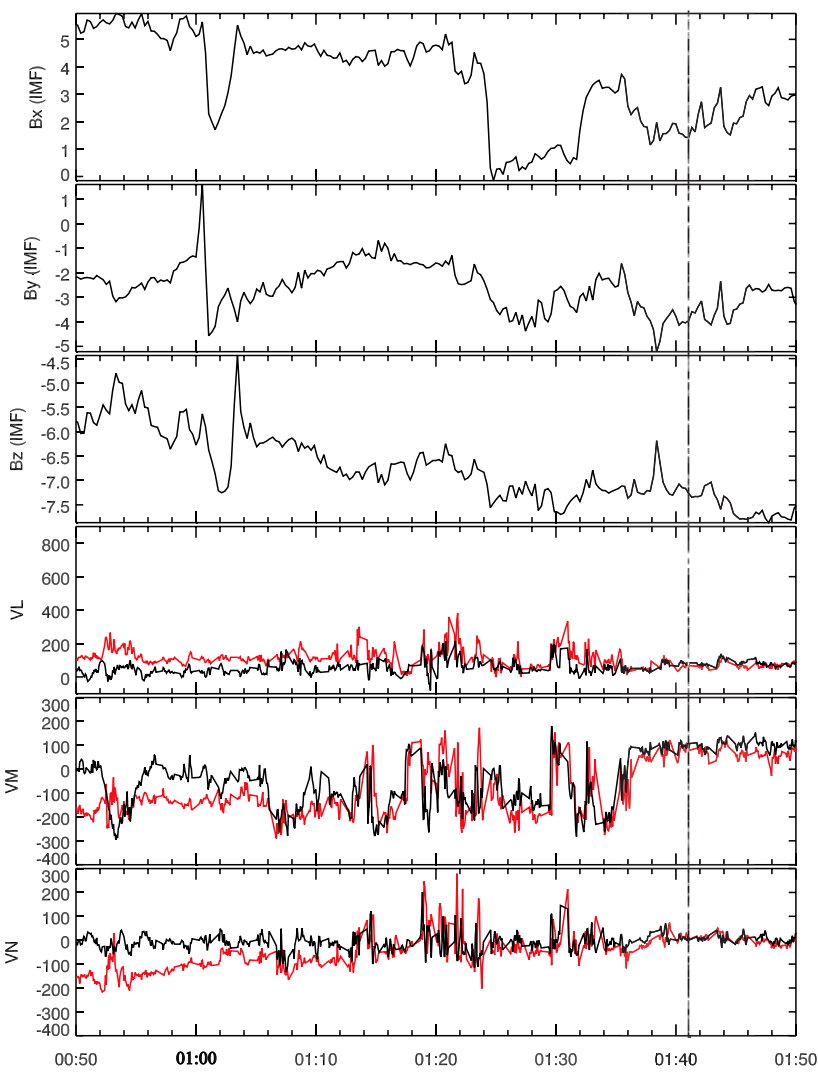

Fig. 7. Comparison between the predicted ion bulk flow velocity and the data for the first type of boundary crossing with small magnetic shear. The prediction used a single magnetosheath point as the reference point. The top three panels are the three components of IMF in GSM. The bottom three panels are the velocity comparison of the three components. The theoretical predication is in red and the data is in black.

used as a measure of the quality of the HT frame. For the existence of a good HT frame, the ratio should be very small $(\ll 1)$.

Two examples of the Walén relation test are shown in Fig. 9. The examples were selected arbitrarily; the left-hand one showing the Walén test of the accelerated flows at the low magnetic shear boundary crossing, and the right-hand one showing the test for the flows at the high magnetic shear crossing. The data interval for the first type (low shear) of boundary crossing analysis is 01:34:30 UT-01:36:00 UT and the reference time is at 01:41:00. The interval for the second type (high shear) of boundary crossing is 02:55:30 UT02:55:50 UT and the reference time is 03:09 UT. The positive slopes of the regression line in Fig. 9 imply that the normal magnetic field points earthward (i.e. $\left.B_{N}<0\right)$ (e.g. Sonnerup et al., 1981), consistent with a reconnection X-line below the spacecraft. The colors in the plots are used to indicate $\mathrm{x}$ (in black), y (red), and z (blue) components, respectively. For the first example, $\mathbf{V}_{H T}$ is $(17.3,62.2,300.5) \mathrm{km} / \mathrm{s}$ in GSM coordinates. For the second example, $\mathbf{V}_{H T}$ is $(-268.9$, $-65.8,290.0) \mathrm{km} / \mathrm{s}$ in GSM. The ratio of $\mathrm{D}_{H T} / \mathrm{D}_{0}$ is 0.080

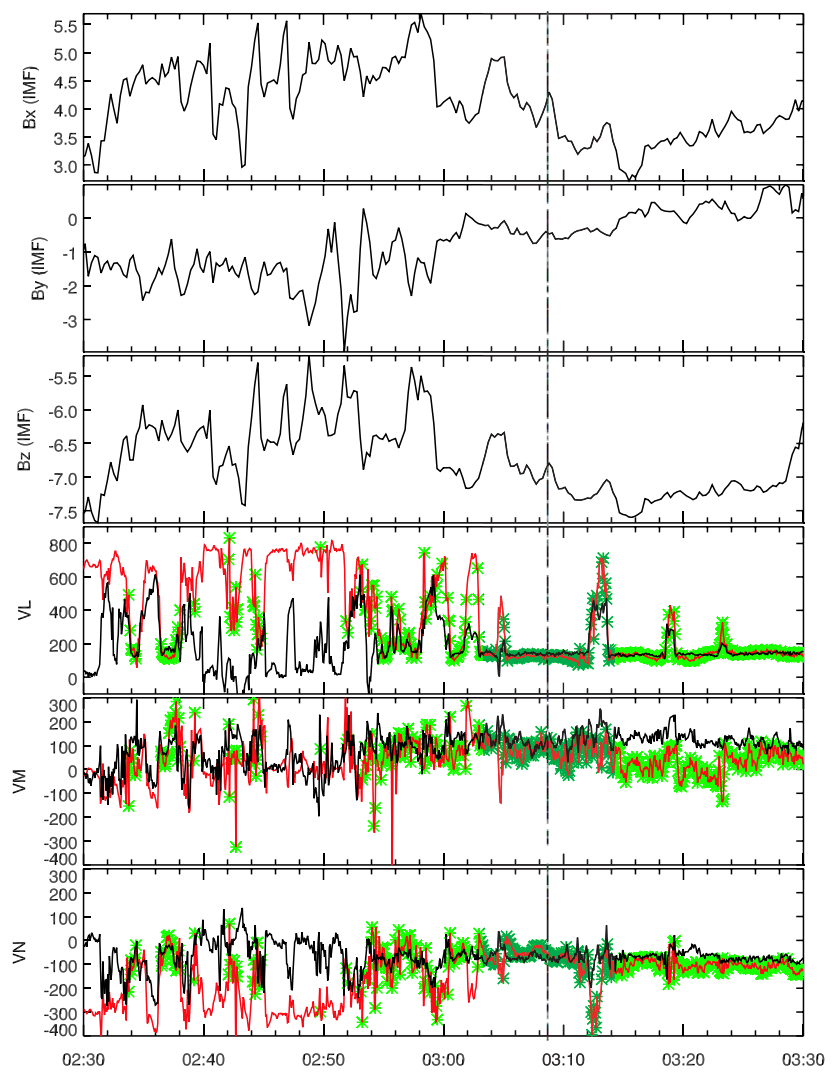

Fig. 8. Comparison between the predicted ion bulk flow velocity and the data for the second type of boundary crossing with large magnetic shear. It has a similar format as Fig. 7, except for the green asterisks, which show the theoretical calculation when the density is above $5 \mathrm{~cm}^{-3}$, to avoid an inappropriate comparison in the region inside the magnetopause which is no longer a rotational discontinuity.

for the first case and 0.088 for the second case. When $\mathbf{v}^{m} \times \mathbf{B}^{m}$ is plotted against $\mathbf{V}_{H T} \times \mathbf{B}^{m}$ (Figs. 9a and c), the best fit has a slope of 1.00 and a correlation coefficient 0.95 for the first case and a slope of 1.00 and a correlation coefficient 0.99 for the second case, indicating that a good HT frame exists for both crossings. Figures $9 \mathrm{~b}$ and $\mathrm{d}$ show that in the HT frame, the flow is $93 \%$ of the Alfvén velocity, for the first example, with a correlation coefficient of 0.98 , and the flow is $83 \%$ of the Alfvén velocity, for the second example, with a correlation coefficient 0.94 . These test results indicate that both the speed and the direction of the observed ion bulk flows are in good agreement with the theoretical prediction, even with the assumption of a 1-D magnetopause and the fact that HIA ion moments are computed assuming that all ions are $\mathrm{H}+$. The $\mathrm{O}+$ density in the jet is about $0.02-$ $0.03 \mathrm{~cm}^{-3}(<0.5 \%$ of the $\mathrm{H}+$ density in the magnetosheath), which is similar to that in the magnetosphere. The presence of heavy ions (such as $\mathrm{O}+$ ) will decrease the Alfvén velocity, and therefore will result in a larger slope in the Walén test plot (such as Figs. 9b and d). But the O+density here is too small to affect the Walén relation. 

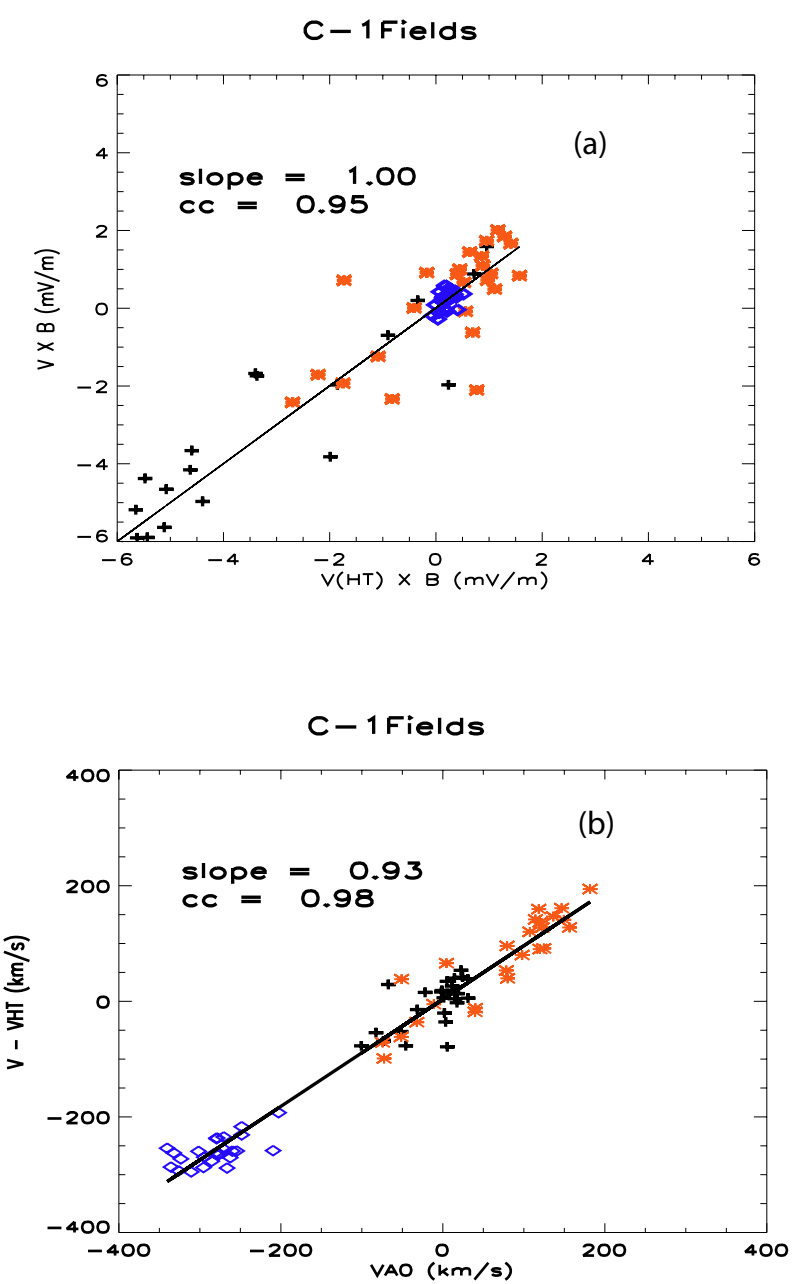
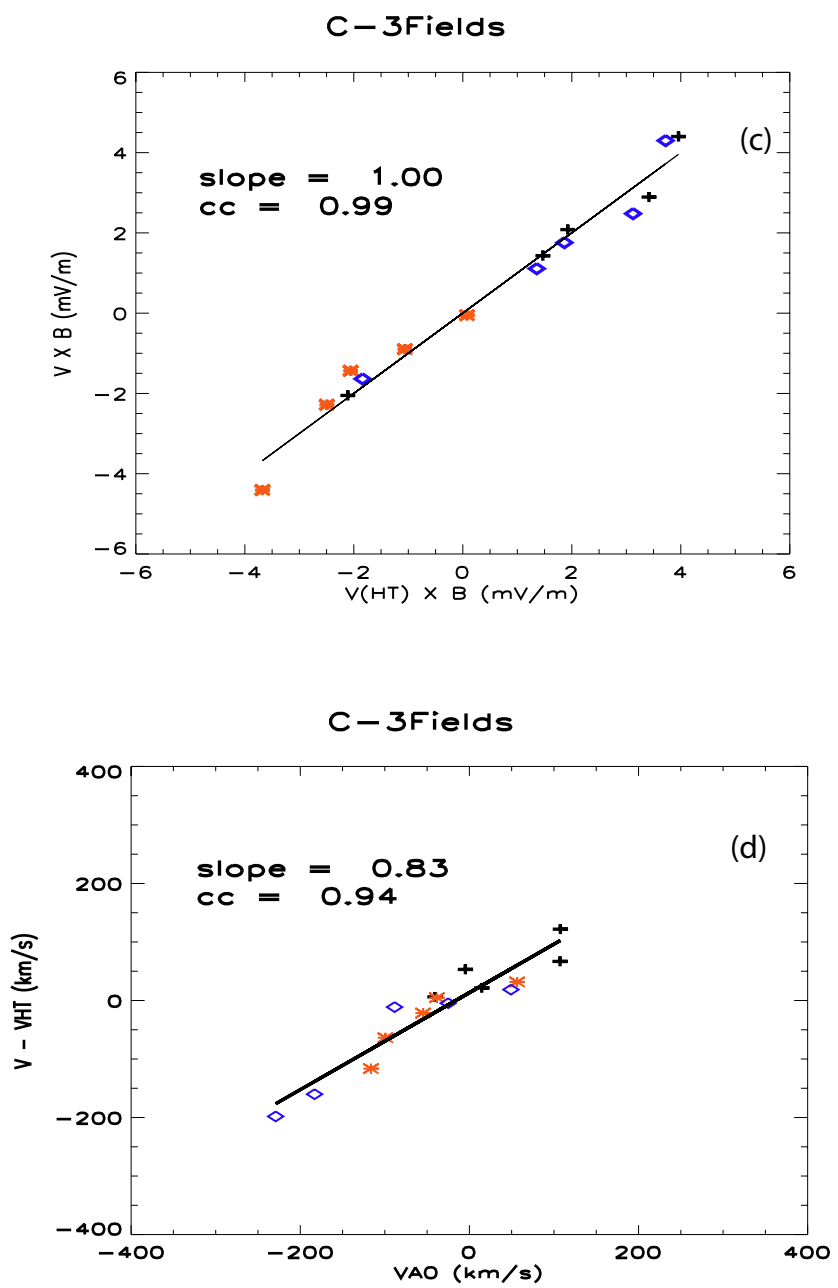

Fig. 9. The Walén relation test results for both types of magnetopause crossings. The two intervals (C1: 01:34:30-01:36:00 UT and C3: 02:55:30-02:55:50 UT) are randomly chosen with the left two panels showing the result for the first type and the right two panels showing the result for the second type. For each type, the top panel is the result of finding the deHoffmann Teller (HT) frame and the bottom panel shows the fitting result of the measured velocity in the HT frame versus the Alfvén velocity.

The tests described above show that the long-lasting accelerated flows observed on 1 April 2003 are caused by reconnection, implying that magnetic reconnection took place continuously over a period of $3 \mathrm{~h}$. Because the magnetopause (MP) is a relatively thin layer with a single spacecraft one can never be certain whether reconnection is operating continuously or not, even though the spacecraft could have multiple encounters with MP and observe high-speed jets for each of the crossings. One can potentially argue that when the spacecraft is not in the MP, the reconnection stops. The four Cluster spacecraft not only extend the potential encounter time with the MP, but also provide more information for determining whether the reconnection is continuous. For this event, the configuration of the four spacecraft was such that $\mathrm{C} 1, \mathrm{C} 2$ and $\mathrm{C} 4$ were in a plane that was close to tangential to the MP, while C3 lagged behind. For the first type (low magnetic shear) of boundary crossing (during the interval of 00:30 UT-02:00 UT), the boundary crossing happened almost continuously because of the spatial arrangement of $\mathrm{C} 1$,
$\mathrm{C} 2$ and $\mathrm{C} 4$. The HIA of $\mathrm{C} 1$ and CODIF of C4 (not shown here) show the observation of accelerated flows whenever either of them was in the MP/boundary layer. The lack of ion data from $\mathrm{C} 2$ may be compensated for by the deduction from the similar features of the four spacecraft magnetic field measurements. All of these points argue strongly that reconnection was operating continuously for the interval. For the second type (high magnetic shear) of MP/boundary crossing (2:00 UT to 3:30 UT), during which $\mathrm{C} 1, \mathrm{C} 2$ and $\mathrm{C} 4$ were already in the magnetosheath (most of the time), the large separation between $\mathrm{C} 3$ and the other spacecraft shows that C3 is the major spacecraft which detected the high-speed jets when it had multiple MP crossings during this interval. During 2:25-2:38 UT, however, because of the motion of the MP (which most likely resulted from reconnection because the solar wind dynamic pressure was weak and relatively stable), C1, C2 and C4 encountered the boundary layer from the magnetosheath side at slightly different times and observed accelerated flows (seen from HIA data of $\mathrm{C} 1$ and CODIF of 


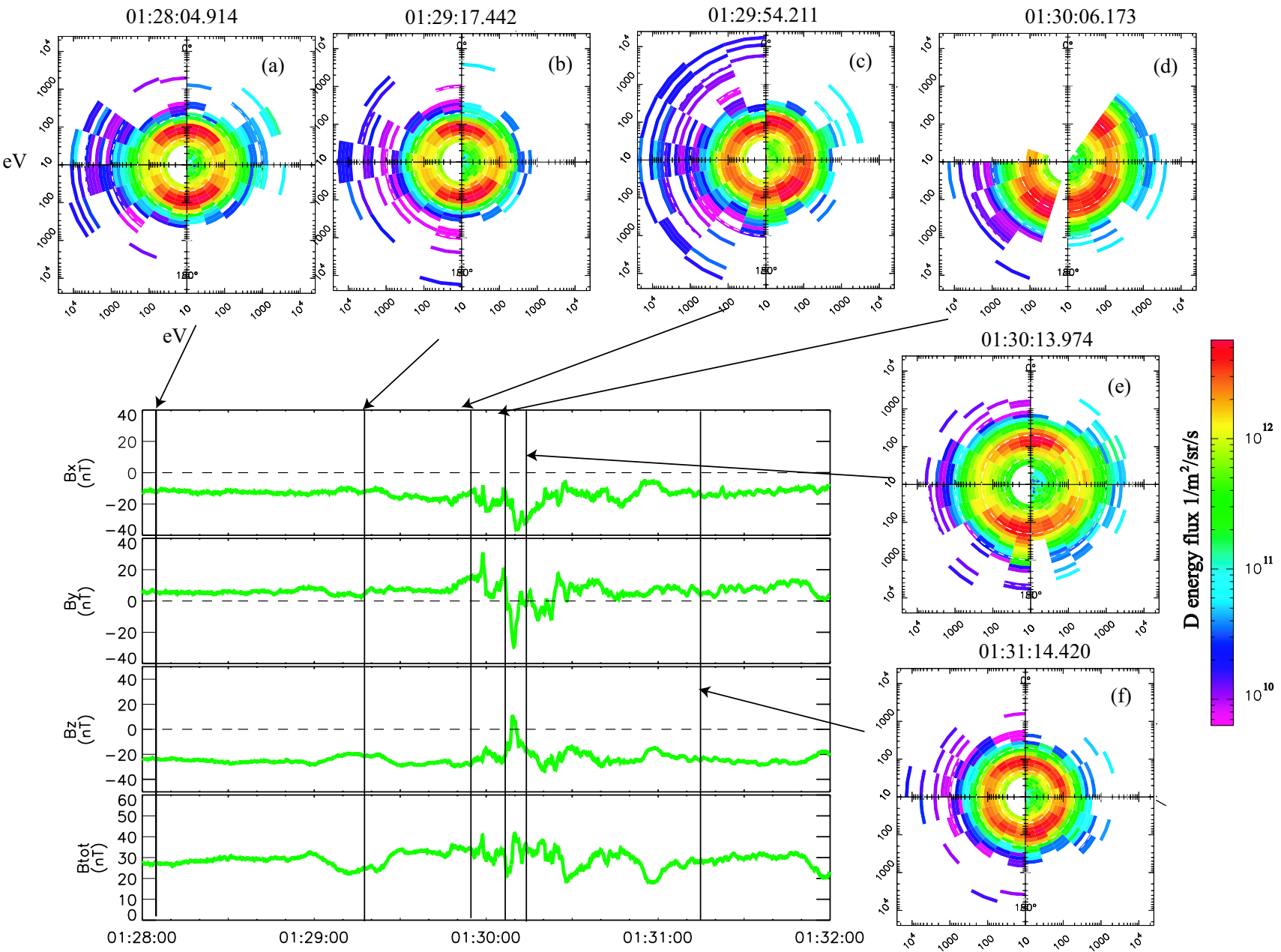

Fig. 10. Electron velocity distribution obtained from PEACE during an interval of the first type boundary crossing. Also shown is the magnetic field data during the interval. The timing of the distributions is indicated in the plot.

C4). In general, the data from all of the spacecraft, combined with the IMF condition at the time, provide good evidence that the reconnection was continuous for about $3 \mathrm{~h}$.

\subsection{Kinetic signatures of reconnection during accelerated} flows - Plasma distributions

We examined the kinetic signatures of reconnection using the electron and ion velocity distributions; first, we show an example related to the first type of boundary crossing, followed by the particle distributions of the second type of boundary crossing.

\subsubsection{Electron distributions}

Figure 10 shows the electron velocity distribution plots (with a 4-s cadence and 118-ms accumulation time), obtained using both the LEEA (Low Energy Electron Analyzer) and HEEA (High Energy Electron Analyzer) of the PEACE instrument during a cusp-magnetosphere interface crossing of C3 (01:28-01:32 UT). LEEA covers the energy range of $0.7 \mathrm{eV}-1 \mathrm{keV}$, HEEA covers the energy range of $30 \mathrm{eV}-$ $26 \mathrm{keV}$ and they are placed on opposite sides of the spacecraft. The corresponding magnetic field profile is also shown for every distribution, as a reference. Shown on top of each distribution is their starting time in UT. The distribution plots are shown in the $\mathrm{V}-\theta$ plane, referenced to the instantaneous high-resolution magnetic field. $\mathrm{V}$ is the magnitude of the electron velocity, shown here in the unit of the electron central energy in $\mathrm{eV}$ and $\theta$ is the pitch angle. The magnetic field direction lies in the vertical axis, with the upper half having a $0^{\circ}$ pitch angle and the lower half having a $180^{\circ}$ pitch angle. The left side of each distribution shows the HEEA data and the right side shows the LEEA data. It should be mentioned that this format assumes that the distributions are gyrotropic. On each of the distributions, the four white circles from the inside out are $50 \mathrm{eV}, 200 \mathrm{eV}, 1 \mathrm{keV}$ and $5 \mathrm{keV}$, respectively. The color in the distribution plots is used to indicate the intensity of the differential energy flux $\left(1 / \mathrm{m}^{2} / \mathrm{s} / \mathrm{sr}\right)$.

The distribution function in both panels $10 \mathrm{a}$ and $\mathrm{b}$ shows counter-streaming fluxes of electrons in the low-energy range 
$(\sim 100 \mathrm{eV})$ and the co-existence of a high-energy population (up to $\sim 10 \mathrm{keV}$ ) centered at the $90^{\circ}$ pitch angle. The counterstreaming fluxes of the electrons in the low-energy range in $10 \mathrm{a}$ and $\mathrm{b}$ do not necessarily imply that $\mathrm{C} 3$ was on the closed field lines at these times; rather the distributions were most likely the incoming $(\sim 100 \mathrm{eV})$ and mirrored magnetosheath electrons on an open field line due to their low energy range. The co-existing population of magnetospheric origin at $90^{\circ}$ pitch angle, together with the absence of the field-aligned magnetospheric electrons, may indicate that at these times C3 was on open field lines at the high-latitude boundary layer.

Figure 10c was obtained at the magnetospheric edge of the magnetopause current layer. The distribution was again composed of two populations, the accelerated magnetosheath electron population and the energetic magnetospheric electrons to above $20 \mathrm{keV}$, which were peaked at $90^{\circ}$. The absence of the field-aligned electrons again indicates an open field line topology, where the field-aligned energetic electrons escaped. Figure 10d and 10e show velocity distributions in the magnetopause current layer where the majority of the electrons are of magnetosheath origin. The magnetosheath electrons were heated dramatically in the magnetopause current layer and were moving towards the Earth (unheated magnetosheath electrons were mostly below the $100 \mathrm{eV}$ range originally, but here we see them heated to 200 $300 \mathrm{eV}$, on average). The observed electron heating in the magnetopause current layer agrees with previous findings by Fuselier et al. (1995) for the low-latitude subsolar region. There were fewer magnetospheric electrons at these times (Fig. 10d and e compared with Fig. 10c). The reason for the missing data at some of the pitch angles in Fig. 10d is due to the fact that the direction of $\mathbf{B}$ moved significantly during the 4-s spin, so that some directions sampled during the $118-\mathrm{ms}$ accumulation of the slice of the distributions were no longer being sampled with respect to the instantaneous $\mathbf{B}$. Figure $10 \mathrm{f}$ is the distribution at the high latitude boundary layer with its distribution similar to Figs. 10a and b, with the exception that its low energy part is more isotropic.

Figure 11 is in the same format as Fig. 10 but for a boundary crossing of the second type, i.e. the magnetopause with a large magnetic shear. Displayed in Fig. 11 are the magnetic field data from 02:25:00 UT to 02:29:00 UT and the electron distributions in five distinct regions: (a) in the magnetosheath, (b) at the magnetosheath edge of the MP current layer, (c) inside the MP current layer, (d) at the earthward edge (magnetospheric side) of the MP current layer, and (e) in the magnetospheric region.

As references, Figs. 11a and e show the distributions of typical cold magnetosheath electrons and tenuous hot magnetospheric electron, respectively. The mixture of magnetospheric and magnetosheath electrons and the heated, earthward-moving magnetosheath electron population in $\mathrm{b}, \mathrm{c}$ and $d$ indicate the interconnection of the magnetic field lines of the two regions. Figures $11 \mathrm{~b} 1$ and $\mathrm{b} 2$ are used to show the evolution of the electrons in the current layer. The times in Figs. 11b, b1 and b2 are $4 \mathrm{~s}$ apart. We can see the dramatic heating of the magnetosheath electrons at all of these times. Again, the incomplete coverage of the pitch angle in Figs. 11 $\mathrm{b}, \mathrm{b} 1, \mathrm{~b} 2, \mathrm{c}$ and $\mathrm{d}$ reflects the rapid changing magnetic field at those times.

Our observations show that heating of the magnetosheath electrons is a common feature in the magnetopause current layer for both types of magnetopause crossings. These observations also favor the view that magnetic reconnection was operating at the time.

\subsubsection{Ion distributions}

Figures 12 and 13 show the ion velocity distributions obtained from the HIA instrument of $\mathrm{C} 3$ in the $\left(V_{\perp}, V_{\|}\right)$plane for two types of MP crossings, respectively. The time interval of Fig. 12 is same as that of Fig. 10 and the time interval of Fig. 13 is the same as in Fig. 11. $V_{\perp}$ is in the $(\mathbf{V} \times \mathbf{B}) \times \mathbf{B}$ direction ( $\mathbf{V}$ is the bulk velocity) and the distributions are collected on board over $12 \mathrm{~s}$. The two-dimensional distributions are plotted in a reference frame moving with the perpendicular bulk velocity. Shown in Fig. 12 are the distributions at the first type of boundary crossing with Figs. 12a and c obtained in the high-latitude boundary layer and Fig. 12b in the MP current layer. When the magnetic shear across the MP is low, we see the mixture of magnetosheath and magnetospheric ions for all three distributions, indicating the open-field line topology. The lack of field-aligned high-energy ions of magnetospheric origin in Figs. 12a and c indicates that they may have escaped along the open-field lines, consistent with the electron distribution in Fig. 10. Meanwhile, Fig. 12b shows that in the magnetopause current layer, the high-energy ions were moving outward along the field line (anti-parallel to B) and the magnetosheath ions were accelerated.

Figure 13 shows the distributions at a high magnetic shear MP crossing in the magnetosheath region (Fig. 13a), in the MP current layer (Figs. 13b, c and d) and in the magnetosphere region (Fig. 13e). Of these, $13 \mathrm{~b}$ is closer to the magnetosheath edge of the current layer, Fig. 13c is in the heart of the MP current layer and Fig. 13d is located at the magnetospheric side of the MP current layer. Similar to the electron distributions during the same interval, the ion distributions here show a mixture of the two populations, as well as strong ion acceleration (see Figs. 13b, c and d). The magnetosheath ions were mostly below $5 \mathrm{keV}$ (corresponding roughly to the $1000 \mathrm{~km} / \mathrm{s}$ in the plots for $\mathrm{H}+$ ) while for the high-energy magnetospheric population, ions below $1.25 \mathrm{keV}$ were absent (see Fig. 13e).

The theory of magnetic reconnection predicts the existence of the D-shaped magnetosheath ion distribution at the MP (Cowley, 1982), and it has been reported widely in the literature (e.g. Gosling et al., 1990a; Fuselier et al., 1991; Smith and Rodgers, 1991; Bauer et al., 1998; Phan et al., 2001). However, D-shaped ion distribution was not observed during our two examples. One could argue that the b,c and $\mathrm{d}$ distributions in Fig. 13 are D-shaped, considering that the magnetic field was highly variable and the distribution was averaged over $12 \mathrm{~s}$. But the fluid and the kinetic signatures at 

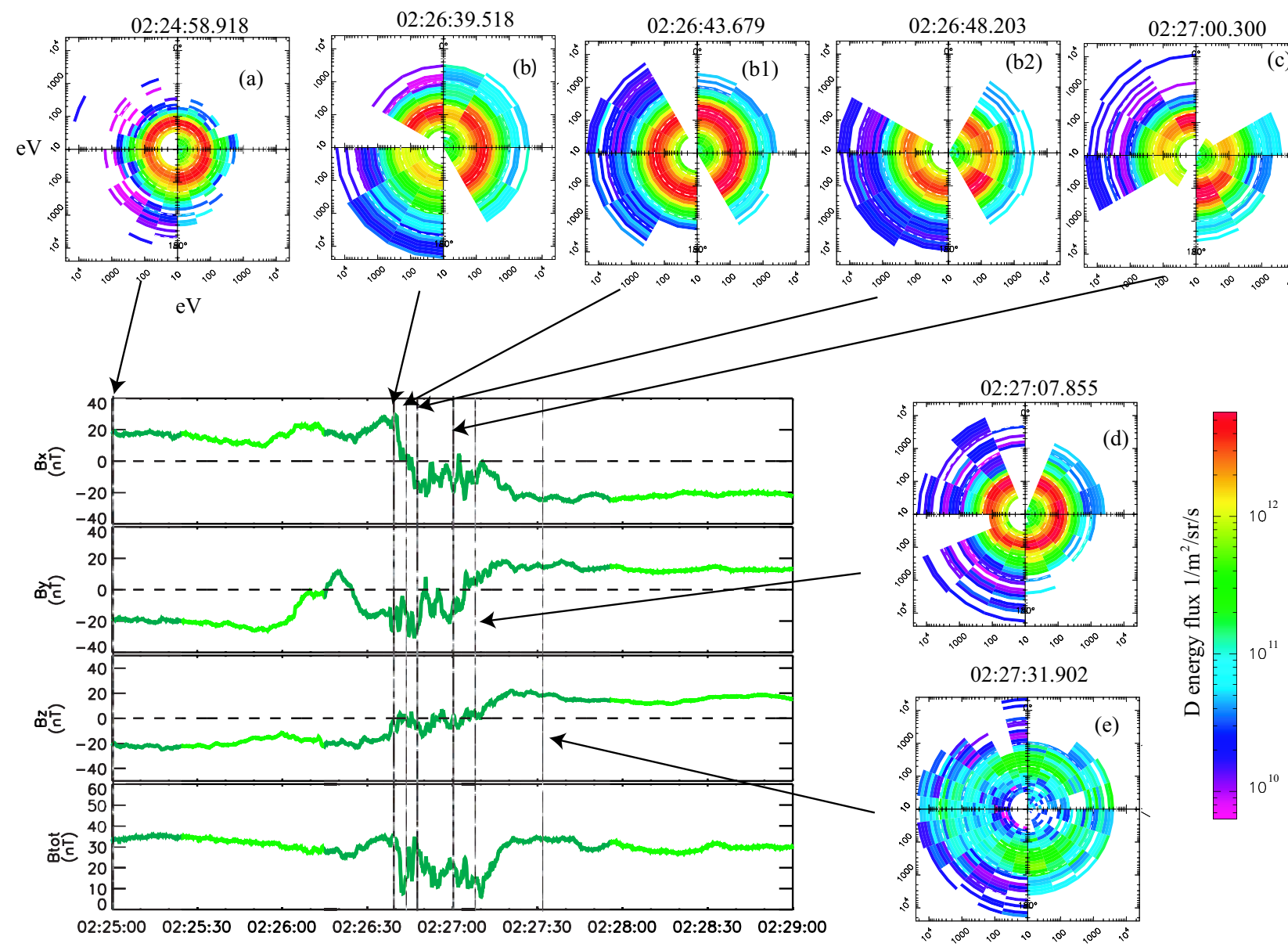

Fig. 11. Electron velocity distribution function during an interval of the second type boundary crossing with large magnetic shear.

the MP do not always appear together, as also reported previously. More often than not, the fluid signatures (Alfvénic flows) are observed without the D-shaped ion distributions, and vice versa (see Bauer et al. (1998)). For further expansion of this, distributions of the two intervals shown in Fig. 10 (during which the fluid signature had excellent agreement with the Walén relation) were also carefully studied, and no D-shaped distributions were found. The absence of the D-shaped ion distributions at and around the MP, in spite of the excellent agreement with the Walén relation, was also reported by Phan et al. (2004). The presence of magnetospheric ions in the magnetosheath side of the MP current layer and the magnetosheath ions earthward of the MP current layer, however, shows that there was transmission of ions across the MP boundary, which is one of the kinetic effects of reconnection.

Another interesting feature to note is that the ion distributions in Figs. 13b, c and d were non-gyrotropic (asymmetric about the $\mathrm{x}$-axis), which probably resulted from magnetic reconnection. The non-gyrotropic distribution is a source of free energy that can excite instabilities. The significance of the non-gytropic ion distributions in the vicinity of the magnetopause requires further investigation.
4.4 Summary of the analyses of the long-lasting high speed plasma jets

The analyses of the prolonged interval of accelerated plasma flows observed at/around the MP and its boundary layers imply that they were most likely caused by magnetic reconnection, as was demonstrated from both fluid and kinetic perspectives. The long-lasting nature of the high-speed flows and their detection by multiple spacecraft also argue strongly that reconnection was operating continuously for more than $3 \mathrm{~h}$. Both the magnetic field and the particle data help reveal many characteristics of the magnetopause current layer. Inside the MP current layer, magnetic field is highly variable and the magnetic field depression is a common feature. We also find that both electrons and ions of magnetosheath origin become heated in the MP current layer, mostly as a result of magnetic reconnection in this case.

\section{Discussion}

To date, the evidence for magnetic reconnection at the magnetopause and its subsequent consequences on the global dynamics of the magnetosphere have been widely reported. 
(a)

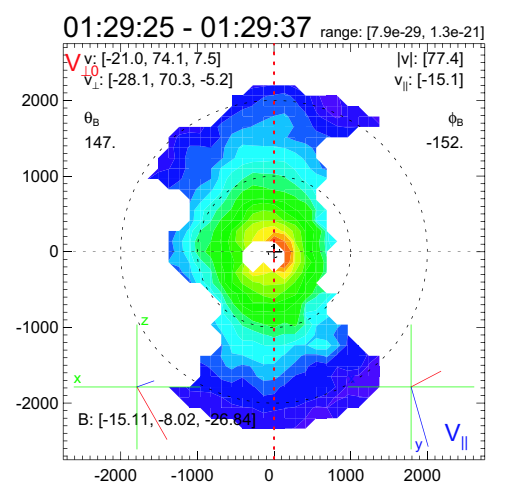

(b)

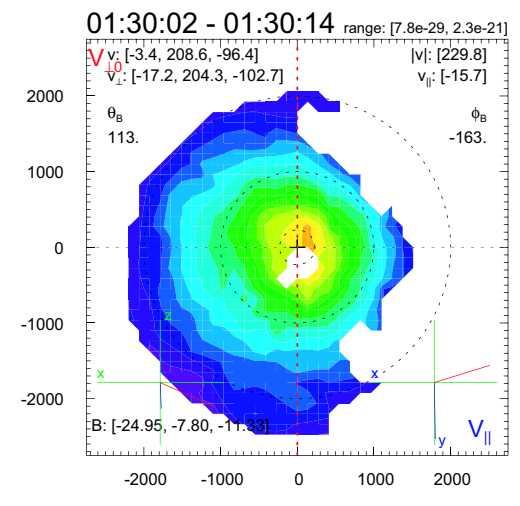

(b)

(a)

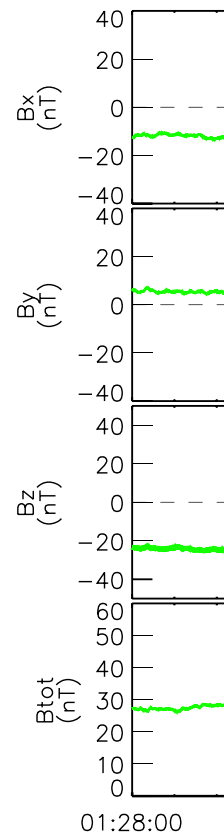

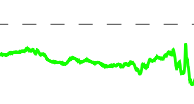
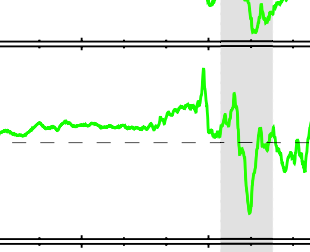

?

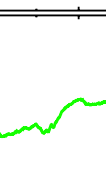

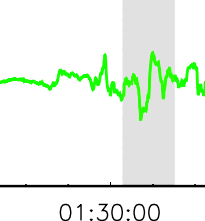

$01: 29: 00$ (c)
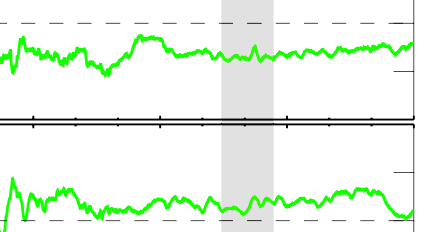

Fig. 12. Ion velocity distribution from HIA during the same interval as shown in Fig. 10, which is of the first type of boundary crossing. The resolution of these distributions is $12 \mathrm{~s}$. The starting time of each distribution is indicated in the magnetic field data.

However, there are still many unanswered questions, including the nature of the physical processes that lead to an initial breakdown; which controls where and when reconnection takes place and at what rate; and which controls the cessation and the temporal behavior of the reconnection once it is initiated (continuous or intermittent). Because signatures of reconnection (e.g. plasma jets) are localized in the thin magnetopause and can therefore only be observed for several minutes as a spacecraft traverses the layer, only a limited number of reports have shown evidence of continuous reconnection (Gosling et al., 1982; Phan et al., 2004; Retinò et al., 2005; and Frey et al., 2003).

The fact that continuous reconnection can take place under both southward (e.g. Phan et al., 2004 and this paper) and northward IMF (e.g. Retinò et al., 2005; Frey et al., 2003) conditions shows that the temporal nature of reconnection is independent of the polarity of IMF and is more likely controlled by externally driven processes or by changes in conditions internal to the magnetosphere.
In contrast to continuous reconnection, intermittent or bursty reconnection has been widely reported in the solar atmosphere where eruptive processes are time-limited (e.g. Priest and Forbes, 2002), at the magnetopause in the form of pulsed reconnection (e.g. Farrugia et al., 1998; Lockwood et al., 1998, 2001; Sandholt et al., 2000; Milan et al., 1999), in flux transfer events (FTEs) (e.g. Russell and Elphic, 1979), and in the magnetotail, where the observation of bursty bulk flows, potentially the analogue of FTEs at dayside, were observed.

Recent observation of continuous reconnection by IMAGE and Cluster calls for a better understanding of which processes/conditions control the different temporal behaviors of magnetic reconnection. How the temporal behavior of reconnection affects the energy input to the magnetosphere from the solar wind is not fully understood, nor do we know which process, continuous reconnection or bursty reconnection, is more efficient in terms of mass, energy and momentum transfer. Quantifying the comparison in terms of measurable 
(a)

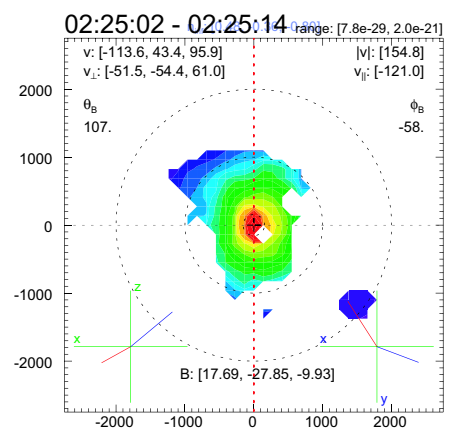

(b)

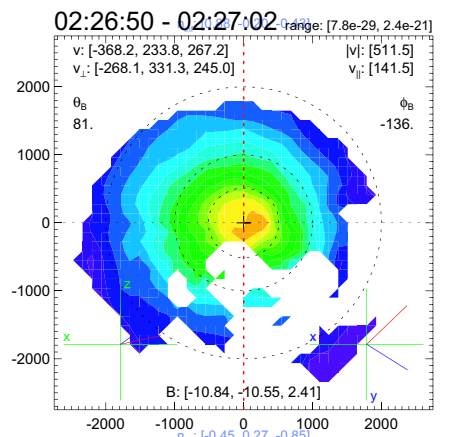

(c)

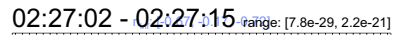

02:27:02 - 02:27:15- range: [7.8e-29, 2.2e-21]

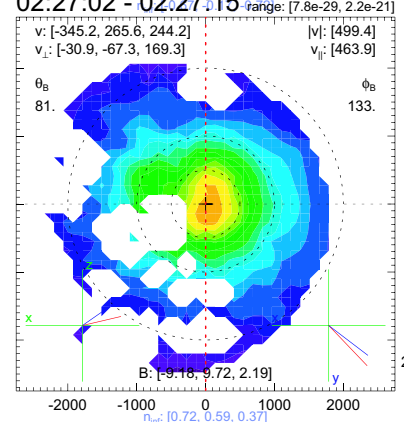

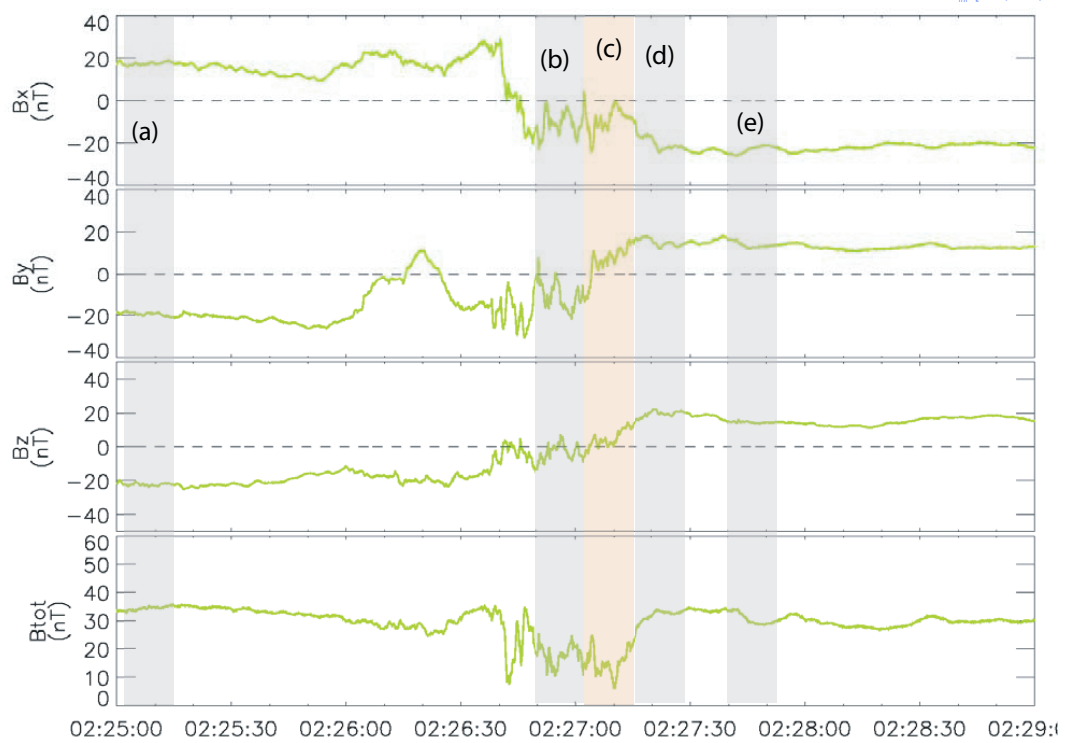

(e)
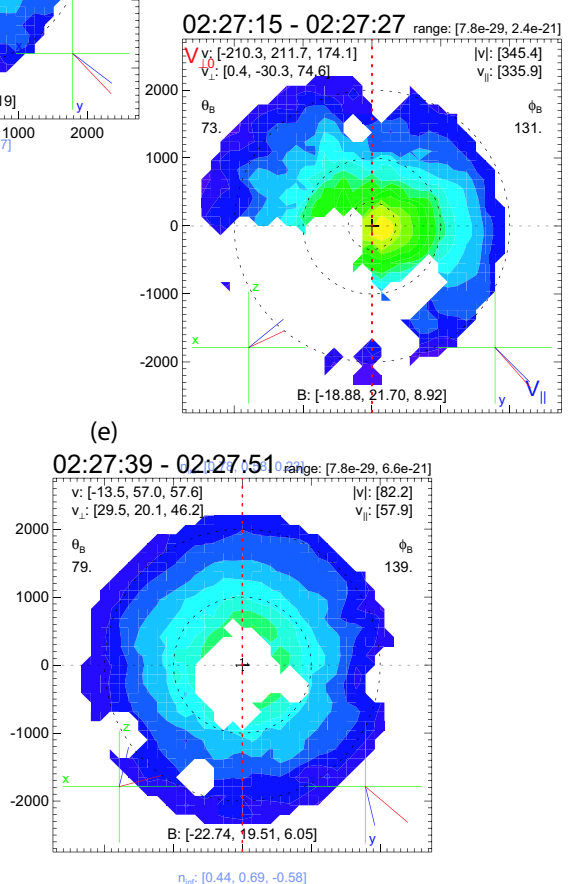

Fig. 13. Ion velocity distribution from HIA during the same interval as shown in Fig. 11, which is of the second type of boundary crossing with large magnetic shear.

physical quantities is another challenge. Answering these questions requires continuous observation of reconnection signatures at the magnetopause, which, at present, are not generally available. Although using ionospheric signatures of reconnection to remotely probe the reconnection characteristics at the magnetopause can serve as an important tool, it too has its own limitations, including a requirement for accurate field line tracing.

A striking feature of this event is that it had very high coupling efficiency in terms of the percentage of solar wind energy being transferred to the magnetosphere-ionosphere (MI) system. The coupling efficiency is defined as the ratio of total energy deposited in the MI system (including total energy of ring current, auroral precipitation, Joule heating and energy in the magnetotail) to the total available solar wind kinetic energy (Østgaard and Tanskanen, 2003). If we use the $\varepsilon$ parameter (Akasofu, 1981) (the semi-empirical parameter of the solar wind energy input to the magnetosphere due to dayside reconnection) as a proxy for the total MI energy, the coupling efficiency is about $32.3 \%$ if the scale length $l_{0}$ is taken as $10 R_{E}$ and would be about $16 \%$ if $l_{0}$ is taken as $7 R_{E}$. Even the $16 \%$ number is very large for the solar wind and
MI coupling, when normally considering the coupling coefficient is below 1\% (Østgaard and Tanskanen, 2003). The large auroral index AE during the event is another indication of the strong coupling between the solar wind, the Earth's magnetosphere, and the ionosphere.

\section{Summary}

A prolonged interval of accelerated plasma flows at high latitude near the northern cusp is studied in detail here. The event took place during 00:00-03:30 UT on 1 April 2003 while Cluster traveled outbound. Besides the long-lasting nature of the accelerated flows, Cluster observed high-speed flows at two different types of MP crossings, one of which had small magnetic shear and the other very large magnetic shear across the MP. The former was at a higher latitude (cusp-magnetosheath interface) than the latter (high-latitude dayside magnetopause). Observations of the event strongly suggest that magnetic reconnection, although time varying, can occur at various locations over a three-hour interval. The 
key observations and interpretations can be summarized as follows:

1. The accelerated flows at the magnetopause/boundary layers had very large flow speed, at times reaching $700 \mathrm{~km} / \mathrm{s}$ (exceeding their adjacent magnetosheath flow speed by $\sim 550 \mathrm{~km} / \mathrm{s}$ ) and they persisted for almost 3 hours. Whenever there was accelerated flow, there was magnetic field rotation or at least variations associated with it.

2. Flow reversals of the y-component of the ion bulk velocity were observed throughout the event (with negative $V_{y}$ in the magnetosheath and positive $V_{y}$ for the accelerated flows at the magnetopause and its boundary layers), which indicates strong acceleration from the magnetic tension force due to reconnection.

3. Accelerated flows were observed at most of the magnetopause crossings. The speed and direction of two randomly selected magnetopause crossings are in excellent agreement with the 1-D model of the reconnecting magnetopause. The accelerated flows observed from the multiple spacecraft during the three and one-half hour interval support the interpretation of continuous reconnection.

4. The persistent north-duskward flow throughout the three and half-hour interval implies that the reconnection site remains southward of the spacecraft at all times. This event shows that magnetic reconnection was in large part controlled by the IMF. However, the observations here cannot pinpoint whether it is component or anti-parallel reconnection that was at work because both theories would give similar observable features given the spacecraft's location and the IMF direction (mostly southward).

5. Plasma jets were observed at two types of magnetopause crossings: one with small magnetic shear and the other with large magnetic shear. This should not be taken as evidence for component reconnection or for antiparallel reconnection, since it is the shear at the $\mathrm{X}$ line, not at the local magnetopause, that matters. The high-speed jets observed at both types of magnetopause crossings most likely resulted from the same reconnection site below the spacecraft.

6. Both electron and ion 3-D velocity distributions show that the plasma was heated at the magnetopause/boundary. Particle signatures resulted from reconnection, such as transmission of plasmas of both regions across the magnetopause, and the open field-line topology can be inferred. However, D-shaped (with the low energy cutoff at the deHoffmann-Teller velocity parallel to the magnetic field) ion distributions were not found even when the fluid features were in good agreement with the Walén relation. Why D-shaped ion distribution occurs in some events and not in others is not well understood.
Acknowledgements. The authors want to thank all of those who have made the Cluster mission a success. Suggestions from T. Phan are gratefully acknowledged. We would also like to thank the referees for their helpful comments. The work was carried out while Y. Zheng held an NRC Resident Research Associate (RRA) fellowship.

Topical Editor T. Pulkkinen thanks I. Wild and another referee for their help in evaluating this paper

\section{References}

Aggson, T. L., Gambardella, P. J., and Maynard, N. C.: Electric field measurements at the magnetopause, 1 , Observation of large convective velocities at rotational magnetopause discontinuities, J. Geophys. Res., 88, 10 000-10 010, 1983.

Akasofu, S.-I.: Energy coupling between the solar wind and the magnetosphere, Space Sci. Rev., 28, 121-190, 1981.

Arnoldy, R. L.: Signature in the interplanetary medium for substorms, J. Geophys. Res., 76, 5189-5201, 1971.

Balogh, A., Carr, C. M., Acuña, M. H., Dunlop, M. W., Beek, T. J., Brown, P., Fornaçon, K.-H., Georgescu, E., Glassmeier, K.H., Harris, J., Musmann, G., Oddy, T., and Schwingerschuh, K.: The Cluster magnetic field investigation: Overview of in-flight performance and initial results, Ann. Geophys., 19, 1207-1217, 2001, SRef-ID: 1432-0576/ag/2001-19-1207.

Bauer, T. M., Paschmann, G., Sckopke, N., Baumjohann, W., Treumann, R. A., and Phan, T. D.: AMPTE-IRM observations of particle and fields at the dayside low-latitude magnetopause, Geospace Mass and Energy Flow: Results from the International Solar-Terrestrial Physics Program, (Eds.) Horwitz, J. L., Gallagher, D. L., and Peterson, W. K., Geophysical Monograph, 104, 51-72, 1998.

Cowley, S. W. H.: The causes of convection in the Earth's magnetosphere: A review of developments during the IMS, Rev. Geophys. Space Phys., 20, 531-565, 1982.

Dungey, J. W.: Interplanetary field and the auroral zones, Phys. Rev. Lett. 6, 47, 1961.

Fairfield, D. H. and Cahill, L. J. Jr.: Transition region magnetic field and polar magnetic disturbances, J. Geophys. Res., 71, 155-169, 1966.

Farrugia, C. J., Sandholt, P. E., Denig, W. F., and Torbert, R. B. Observation of a correspondence between poleward moving auroral forms and stepped cusp ion precipitation, J. Geophys. Res., 103, 9309-9315, 1998.

Frey, H. U., Phan T. D., Fuselier, S. A., and Mende, S. B.: Continuous magnetic reconnection at Earth's magnetopause, Nature 426, 533-537, 2003.

Fuselier, S. A., Klumpar, D. M., and Shelley, E. G.: Ion reflection and transmission during reconnection at the Earth's subsolar magnetopause, Geophys. Res. Lett., 18, 139-142, 1991.

Fuselier, S. A.: Kinetic aspects of reconnection at the magnetopause, in: Physics of the magnetopause, Geophys. Monogr. Ser., Vol. 90, (Eds.) Song, P., Sonnerup, B. U. Ö., and Thomsen, M. F., AGU, Washington, D. C., 181-187, 1995.

Fuselier, S. A., Trattner, K. H., and Petrinec, S. M.: Cusp observations of high and low-latitude reconnection for northward interplanetary magnetic field, J. Geophys. Res., 105, 253-266, 2000.

Gosling, J. T., Asbridge, J. R., Bame, S. J., Feldman, W. C., Paschmann, G., Sckopke, N., and Russell C. T.: Evidence for 
quasi-stationary reconnection at the dayside magnetopause, $\mathrm{J}$. Geophys. Res, 87, 2147-2158, 1982.

Gosling, J. T., Thomsen, M. F., Bame, S. J., and Russell C. T.: Accelerated flows at the near-tail magnetopause, J. Geophys. Res., 91, 3029-3041, 1986.

Gosling, J. T., Thomsen, M. F., Bame, S. J., Elphic, R. C., and Russell, C. T.: The electron edge of the low latitude boundary layer during accelerated flow events, Geophys. Res., Lett., 17, 1833-1836, 1990a.

Gosling, J. T., Thomsen, M. F., Bame, S. J., Elphic, R. C., and Russell, C. T.: Cold ion beams in the low latitude boundary layer during accelerated flow events, Geophys. Res. Lett., 17, 22452248, 1990b.

Gosling, J. T., Thomsen, M. F., Bame, S. J., Elphic, R. C., and Russell, C. T.: Plasma flow reversals at the dayside magnetopause and the origin of asymmetric polar cap convection, J. Geophys. Res., 95, 8073-8084, 1990c.

Gosling, J. T., Thomsen, M. F., Bame, S. J., Elphic, R. C., and Russell, C. T.: Observations of reconnection of interplanetary and lobe magnetic field lines at the high-latitude magnetopause, J. Geophys. Res., 96, 14 097-14 106, 1991.

Gustafsson, G., Boström, R., Holback, B., Holmgren, G., Lundgren, A., Stasiewicw, K., Åhlèn, L., Mozer, F. S., Pankow, D., Harvey, P., Ulrich, R., Pedersen, A., Schmidt, R., Butler, A., Fransen, A. W. C., Klinge, D., Thomsen, M., Fälthammar, C.-G., Lindqvist, P.-A., Christenson, S., Holtet, J., Lybekk, B., Sten, T. A., Tanskenen, P., Lappalainen, K., and Wygant, J: The electric field and wave experiment for the Cluster Mission, Space Sci. Rev., 79, 137-156, 1997.

Hudson, P. D.: Discontinuities in an anisotropic plasma and their identification in the solar wind, Planet. Space. Sci., 18, 1611$1622,1970$.

Johnstone, A. D., Alsop, C., Burge, S., Carter P. J., Coates, A. J., Coker, A. J., Fazakerley, A. N., Grande, M., Gowen, R. A., Gurgiolo, C., Hancock, B. K., Narheim, B., A. Preece, A., Sheather, P. H, Winningham, J. D., and Woodliffe, R. D.: Peace: A Plasma Electron and Current Experiment, Space Sci. Rev. 79, 351-398, 1997.

Levy, R. H., Petschek, H. E., and Siscoe, G. L.: Aerodynamic aspects of the magnetospheric flow, AIAA J. 2, 2065-2076, 1964.

Lockwood, M., Davis, C. J., Onsager, T. J., and Scudder, J. D.: Modeling signatures of pulsed magnetopause reconnection in cusp ion dispersion signatures seen at middle altitudes. Geophys. Res. Lett., 25, 591-594, 1998.

Lockwood, M., Milan, S. E., Onsager, T., Perry, C. H., Scudder, J. A., Russell, C. T., and Brittnacher, M.: Cusp ion steps, fieldaligned currents and poleward moving auroral forms, J. Geophys. Res., 106, 29 555-29 569, 2001.

McComas, D. J., Bame, S. J., Barber, P., Fieldman, W. C., Phillips, J. L., and Riley, P.: Solar wind electron, proton, and alpha monitor (SWEPAM) on the Advanced Composition Explorer, Space Sci. Rev., 86, 563-612, 1998

Milan, S. E., Lester, M., Greenwald, R. A., and Sofko, G.: The ionospheric signature of transient dayside reconnection and the associated pulsed convection return flow, Ann. Geophys., 17, 11661171, 1999,

SRef-ID: 1432-0576/ag/1999-17-1166.

Mozer, F. S., Bale, S. D., and Phan, T. D.: Evidence of diffusion regions at a subsolar magnetopause crossing, Phys. Rev. Lett., 89, No. 1, 015002(4), 2002

Østgaard, N. and Tanskanen, E.: Energetics of isolated and stormtime substorms, in: Disturbances in Geospace:
The Storm-Substorm Relationship, Geophys. Monogr., 142, doi:10.1029/142GM14, 2003.

Paschmann, G., Sonnerup, B. U. Ö., Papamastorakis, I., Sckopke, N., Haerendel, G., Bame, S. J., Asbridge, J. R., Gosling, J. T., Russell, C. T., and Elphic, R. C.: Plasma acceleration at the Earth's magnetopause, Evidence for magnetic reconnection, Nature, 282, 243-246, 1979.

Paschmann, G., Papamastorakis, I., Baumjohann, W., Sckopke, N., Carlson, C. W., B. U. Ö. Sonnerup, B. U. Ö., and Lühr, H.: The magnetopause for large magnetic shear, AMPTE/IRM observations, J. Geophys. Res., 91, 11/,099-11/,119, 1986.

Phan, T. D., Paschmann, G., and Sonnerup, B. U. Ö.: Low-latitude dayside magnetopause and boundary layer for high magnetic shear 2. Occurrence of magnetic reconnection, J. Geophys. Res., 101, 7871-7828, 1996.

Phan, T. D., Kistler, L. M., Klecker, B., Haerendel, G., Paschmann, G., Sonnerup, B. U. Ö., Baumjohann, W., Bavassano-Cattaneo, M. B., Carlson, C. W., DiLellis, A. M., Fornacon, K.-H., Frank, L. A., Fujimoto, M., Georgescu, E., Kokubun, S., Moebius, E., Mukai, T., Øieroset, M., Paterson, W. R., and Reme, H.: Extended magnetic reconnection at the Earth's magnetopause from detection of bi-directional jets, Nature 404, 848-850, 2000.

Phan, T. D., Sonnerup, B. U. Ö., and Lin, R. P.: Fluid and kinetics signatures of reconnection at the dawn tail magnetopause: Wind observations, J. Geophys. Res., 106A11, 25 489-25 501, 2001.

Phan, T., Frey, H. U., Frey, S., Peticolas, L., Fuselier, S., Carlson, C., Rème, H., Bosqued, J.-M., Balogh, A., Dunlop, M., Kistler, L., Mouikis, C., Dandouras, I., Sauvaud, J.-A., Mende, S., McFadden, J., Parks, G., Moebius, E., Klecker, B., Paschmann, G., Fujimoto, M., Petrinec, S., Marcucci, M. F., Korth, A., and Lundin, R.: Simultaneous Cluster and IMAGE observations of cusp reconnection and auroral proton spot for northward IMF, Geophy. Res. Lett., 30(10), 1509, doi:10.1029/2003GL016885, 2003.

Phan T. D., Dunlop, M. W., Paschmann, G., Klecker, B., Bosqued, J. M., Rème, H., Balogh, A., Twitty, C., Mozer, F. S., Carlson, C. W., Mouikis, C., and Kistler, L. M.: Cluster observations of continuous reconnection at the magnetopause under steady interplanetary magnetic field conditions, Ann. Geophys., 22, 23552367, 2004,

SRef-ID: 1432-0576/ag/2004-22-2355.

Priest, E. R. and Forbes, T. G.: The magnetic nature of solar flares, Astron. and Astrophys. Rev., 10(4), 313-377, 2002.

Rème, H., Aoustin, C., and Bosqued, J. M. et al.: First multispacecraft ion measurements in and near the Earth's magnetosphere with the identical Cluster Ion Spectrometry (CIS) experiment, Ann. Geophys., 19, 1303-1354, 2001,

SRef-ID: 1432-0576/ag/2001-19-1303.

Retinò, A., Bavassano Cattaneo, M. B., Marcucci, M. F., Vaivads, A., André, M., Khotyaintsev, Y., Phan, T., Pallocchia, Rème, H., Moebius, E., Klecker, B., Carlson, C. W., McCarthy, M., Korth, A., Lundin, R., and Balogh, A.: Cluster multispacecraft observations at high-latitude duskside magnetopause: implications for continuous and component magnetic reconnection, Ann. Geophys., in press, 2005.

Rostoker, G. and Fälthammar, C.: Relationship between changes in the interplanetary magnetic field and variations in the magnetic field at the Earth's surface, J. Geophys. Res., 72, 5853-5863, 1967.

Russell, C. T. and Elphic, R. C.: ISEE observations of flux transfer events at the dayside magnetopause, Geophys. Res. Lett., 6., 3336,1979 . 
Sandholt, P. E., Farrugia, C. J., Cowley, S. W. H., et al.: Dynamic cusp aurora and associated pulsed reverse convection during northward interplanetary magnetic field, J. Geophys. Res. 105, 12 869-12 894, 2000.

Scudder, J. D., Mozer, F. S., Maynard, N. C., and Russell, C. T.: Fingerprints of collisionless reconnection at the separator, I, Ambipolar-Hall signatures, J. Geophys. Res., 107(A10), 1294, doi:10.1029/2001JA000126, 2002.

Scurry, L., Russell, C. T., and Gosling, J. T.: Geomagnetic activity and the beta dependence of the dayside reconnection rate, J. Geophys. Res., 99, 14 811-14 814, 1994a.

Scurry, L., Russell, C. T., and Gosling, J. T.: A statistical study of accelerated flow events at the dayside magnetopause, J. Geophys. Res., 99, 14 815-14 829, 1994b.

Shue, J.-H., Chao, J. K., Fu H. C., Russell, C. T., Song, P., Khurana, K. K., and Singer, H. J.: A new functional form to study the solar wind control of the magnetopause size and shape, J. Geophys. Res., 102, 9497-9511, 1997.

Siscoe, G. L., Davis, L. Jr., Coleman, P. J. Jr., Smith, E. J., and Jones, D. E.: Power spectra and discontinuities of the interplanetary magnetic field: Marina 4, J. Geophys. Res., 73, 61-82, 1968.

Smith, C. W., Acuna, M. H., Burlaga, L. F., L'Heureux, J., Ness, N. F., and Scheifele, J.: The ACE Magnetic Field Experiment, Space Sci. Rev., 86, 613-632, 1998.
Smith, M. F. and Rodgers, D. J.: Ion distributions at the dayside magnetopause, J. Geophys. Res., 96, 11 617-11 624, 1991.

Sonnerup, B. U. Ö, Paschmann, G., Papamastorakis, I., Sckopke, N., Haerendel, G., Bame, S. J., Asbridge, J. R., Gosling, J. T., and Russell, C. T.: Evidence for magnetic reconnection at the Earth's magnetopause, J. Geophys. Res., 86, 10 049-10 067, 1981.

Sonnerup, B. U. Ö, Papamastorakis, I., Paschmann, G., and Lühr, H.: Magnetopause properties from AMPTE/IRM observations of the convection electric field: Method development, J. Geophys. Res., 92, 12 137-12 159, 1987.

Sonnerup, B. U. Ö, Papamastorakis, I., Paschmann, G., and Lühr, H.: The magnetopause for large magnetic shear: Analysis of convection electric fields from AMPTE/IRM, J. Geophys. Res., 95, 10541-10 557, 1990.

Sonnnerup, B. U. Ö, Paschmann, G., and Phan, T. D.: Fluid aspects of reconnection at the magnetopause: in-situ measurements, in Physics of the Magnetopause, Geophys. Monogr. Ser. Vol. 90, (Eds.) Song, P., Sonnerup, B. U. Ö., and Thomsen, M. F., 167180, AGU, Washington, D. C., 1995.

Tsyganenko, N. A.: Modeling the Earth's magnetospheric magnetic field confined within a realistic magnetopause, J. Geophys. Res., 100, 5599-5612, 1995. 